\title{
Characterization of a Nicotine-Sensitive Neuronal Population in Rat Entorhinal Cortex
}

\author{
Bin Tu, Zhenglin Gu, Jian-xin Shen, Patricia W. Lamb, and Jerrel L. Yakel \\ Laboratory of Neurobiology, National Institute of Environmental Health Sciences, National Institutes of Health, Department of Health and Human Services, \\ Research Triangle Park, North Carolina 27709
}

The entorhinal cortex (EC) is a part of the hippocampal complex that is essential to learning and memory, and nicotine affects memory by activating nicotinic acetylcholine receptors (nAChRs) in the hippocampal complex. However, it is not clear what types of neurons in the EC are sensitive to nicotine and whether they play a role in nicotine-induced memory functions. Here, we have used voltage-sensitive dye imaging methods to locate the neuronal populations responsive to nicotine in entorhino-hippocampal slices and to clarify which nAChR subtypes are involved. In combination with patch-clamp methods, we found that a concentration of nicotine comparable to exposure during smoking depolarized neurons in layer VI of the EC (ECVI) by acting through the non- $\alpha 7$ subtype of nAChRs. Neurons in the subiculum (Sb; close to the deep EC layers) also contain nicotine-sensitive neurons, and it is known that Sb neurons project to the ECVI. When we recorded evoked EPSCs (eEPSCs) from ECVI neurons while stimulating the Sb near the CA1 region, a low dose of nicotine not only enhanced synaptic transmission (by increasing eEPSC amplitude) but also enhanced plasticity by converting tetanus stimulationinduced short-term potentiation to long-term potentiation; nicotine enhanced synaptic transmission and plasticity of ECVI synapses by acting on both the $\alpha 7$ and non- $\alpha 7$ subtypes of nAChRs. Our data suggest that ECVI neurons are important regulators of hippocampal function and plasticity during smoking.

\section{Introduction}

Nicotine is the major compound in tobacco that affects memory (Peeke and Peeke, 1984; McGehee and Role, 1996) and cognition (Potter and Newhouse, 2008) through its actions on nicotinic acetylcholine receptors (nAChRs) (Dajas-Bailador and Wonnacott, 2004; Davis et al., 2007; Timmermann et al., 2007). Despite the negative health consequences of smoking tobacco, nicotine and related compounds have been proposed as drugs for treating neurological diseases and disorders including Alzheimer's disease (Levin and Rezvani, 2002; Levin et al., 2006), Parkinson's disease (Park et al., 2007; Quik et al., 2007a,b; Villafane et al., 2007), attention-deficit hyperactivity disorder (Potter and Newhouse, 2008), schizophrenia (Tizabi, 2007), and epilepsy (Shin et al., 2007) because of their effects on memory, cognition, and neuronal excitability. However, the mechanisms by which nicotine influences memory and learning are far from understood.

The hippocampal formation (HF) is critical to memory and cognition (Blozovski, 1983; Izquierdo et al., 2008) and mediates the influences of nicotine on memory (Blozovski, 1985; Davis et al., 2007). The HF includes four main subregions (Amaral and Witter, 1995): the dentate gyrus, the hippocampal proper (including CA1, CA2, and CA3 regions), the subicular complex

Received June 2, 2009; revised July 20, 2009; accepted July 22, 2009.

This work was supported by the Intramural Research Program of the National Institutes of Health-National Institute of Environmental Health Sciences. We are grateful to Drs. David Armstrong, J. Victor Nadler, Serena Dudek, and Christian Erxleben for providing valuable suggestions in experiments and in the writing of this manuscript.

Correspondence should be addressed to Jerrel L. Yakel, National Institute of Environmental Health Sciences,

F2-08, P.0. Box 12233, 111 T. W. Alexander Drive, Research Triangle Park, NC 27709. E-mail: yakel@niehs.nih.gov. D0I:10.1523/JNEUROSCI.2580-09.2009

Copyright $\odot 2009$ Society for Neuroscience ～0270-6474/09/2910436-13\$15.00/0 [including subiculum (Sb)], and the entorhinal cortex (EC; including layers I-VI). Each subregion plays distinct roles in memory and cognition (Hunsaker et al., 2008; Li and Chao, 2008). Thus far, investigations regarding the influence of nicotine on hippocampal neurons have been focused on the hippocampal proper and dentate regions (Jones and Yakel, 1997; Frazier et al., 1998a,b; McQuiston and Madison, 1999; Sudweeks and Yakel, 2000; Alkondon and Albuquerque, 2001; Khiroug et al., 2003; Fayuk and Yakel, 2004, 2005; Klein and Yakel, 2005; Welsby et al., 2007); this is likely because of the well studied role of this region in learning and memory (Hasselmo, 2005; Lee et al., 2005; Chen et al., 2006; Hunsaker et al., 2008; Izquierdo et al., 2008; Li and Chao, 2008) and the ability of nicotine to induce synaptic potentiation (Hunter et al., 1994; Sawada et al., 1994; Gray et al., 1996; Fujii et al., 1999, 2000; He et al., 2003; Matsuyama et al., 2000). However, whether nicotine influences neurons in either the subicular complex or EC is still unknown. Because both the EC and Sb play critical roles in memory functions (Blozovski, 1983, 1985; O'Mara et al., 2001; Deadwyler and Hampson, 2004; Burhans and Gabriel, 2007; Martin-Fardon et al., 2007; Harich et al., 2008; Izquierdo et al., 2008; Van Cauter et al., 2008), information about whether and how nicotine influences these structures is important in understanding how nicotine affects memory.

To address this issue, we introduced voltage-sensitive dye imaging (VSDI) techniques to locate the neuronal populations responsive to nicotine in entorhino-hippocampal slices and to clarify which nAChR subtypes are involved. Nicotine was bath applied to emulate systematic administration occurring during smoking, while using nicotine patches, or during subcutaneous injection. Patch-clamp techniques were then used to characterize 
the receptors and neuronal populations involved and their role in synaptic plasticity.

\section{Materials and Methods}

Slice preparation. Wistar rats $\sim 14-21 \mathrm{~d}$ of age were anesthetized with halothane and decapitated. Brains were quickly removed; placed into a high-magnesium/low-calcium ice-cold artificial CSF (the dissecting ACSF) containing (in mM) $122 \mathrm{NaCl}, 3.5 \mathrm{KCl}, 12 \mathrm{MgCl}_{2}, 1.3 \mathrm{CaCl}_{2}, 1.2$ $\mathrm{NaH}_{2} \mathrm{PO}_{4}, 25 \mathrm{NaHCO}_{3}, 0.5$ ascorbic acid, and 10 glucose; and continuously bubbled with carboxygen $\left(95 \% \mathrm{O}_{2} / 5 \% \mathrm{CO}_{2}\right)$. Horizontal entorhinohippocampal slices ( $\sim 300-450 \mu \mathrm{m}$ thick) corresponding to plate $190-200$ of the Paxinos rat brain atlas (Paxinos and Watson, 2007) were prepared in icy carboxygenated dissecting ACSF with a vibratome. Slices were then stored in the regular ACSF (same as the dissecting ACSF except with 1.8 $\mathrm{mm} \mathrm{CaCl} 2$ and $1.2 \mathrm{mM} \mathrm{MgCl}_{2}$ ) and continuously bubbled with carboxygen at room temperature for $>1 \mathrm{~h}$ before use.

VSDI. The VSDI technique was modified from a previous report (Tominaga et al., 2000) to conduct longer-duration imaging sampling (see Fig. 1A). After at least $1 \mathrm{~h}$ of recovery from slicing, 400- or $450-\mu \mathrm{m}$-thick slices were stained (away from light) for 45-60 min in a oxygenated humidity chamber with staining solution containing either Di-4-ANNEPS or $\mathrm{N}$-(3-triethylammoniumpropyl)-4-(4-(dibutylamino)styryl)pyridinium dibromide (FM 1-43; both $100 \mu \mathrm{M}$ ), 50\% FBS, 50\% regular ACSF, $0.1 \%$ cremophor EL, and $2 \%$ ethanol. The stained slice was then placed in an MS3 microscope stage interface chamber (Automate Scientific) over a white FHLC membrane $(0.45 \mu \mathrm{m}$; Millipore $)$ supported by a nylon mesh (Warner Instruments) that was raised $250 \mu \mathrm{m}$ above the chamber bottom. Humidified carboxygen was blown over the top of the slice with perfusion medium flowing beneath the FHLC membrane to make sure that the top of the slice was humidified but not covered with liquid; this was a critical step to ensure low-noise imaging while maintaining viability of neurons. Perfusion medium was delivered to the chamber at a rate of $\sim 1.5-2 \mathrm{ml} / \mathrm{min}$ driven by gravity (see Fig. $1 A$ ). A THT microscope (BrainVision) was used to acquire VSDI signals and was equipped with epifluorescence optics in a tandem-lens configuration: PLANAPO $1 \times$ lens $(\mathrm{WD}, 55 \mathrm{~mm}$; Leica) as the objective lens and PLANAPO $0.63 \times$ lens $(\mathrm{WD}, 97 \mathrm{~mm}$; Leica) as the projection lens. The final magnification of the system was 1.6. The excitation light was provided by a halogen lamp source ( $150 \mathrm{~W}$; MHAB-150W; Moritex) passed through an excitation filter (510-550 nm; FF01-531/40-25; Semrock). Light was reflected onto the slice by a dichroic mirror $(570 \mathrm{~nm})$, and the fluorescence generated from slices was passed through an emission filter (>590 nm; U-MWG2 filter set; Olympus). Images were projected onto the $6.4 \times 4.8 \mathrm{~mm}^{2} \mathrm{CCD}$ sensor of the optical imaging system (MiCAM02-HR; BrainVision). Imaging responses to stimulation were acquired at a speed of $5 \mathrm{~ms}$ per frame with an actual size of $184 \times 124$ pixels (spatial resolution of $22 \times 24 \mu \mathrm{m}$ per pixel) for $500 \mathrm{~ms}$. Imaging of nicotine effects was acquired at 1 or $5 \mathrm{~s}$ per frame $(376 \times 252$ pixel dimension, $11 \times 12 \mu \mathrm{m}$ per pixel), with $50 \mathrm{~ms}$ exposure time for each frame to minimize photobleaching. Imaging acquisition was performed at room temperature in all experiments.

Field recordings. A glass pipette (tip diameter, $\sim 1 \mu \mathrm{m}$ ), pulled from borosilicate glass capillaries (Garner Glass) with a model P-97 puller (Sutter Instrument Company) and filled with $2 \mathrm{M} \mathrm{NaCl}$ (resistance, $\sim 3-10 \mathrm{M} \Omega$ ), was placed in regions of interest. Stimulation was delivered through a bipolar platinum/iridium electrode $(25 \mu \mathrm{m}$ thick insulated with formvar; FHC) to specified regions. Field potential signals were amplified 1000 times and bandpass filtered at $0.3-3000 \mathrm{~Hz}$ with a P511 AC amplifier (Grass Technologies). Amplified signals were digitized with a Digidata 1322A, acquired, and analyzed with pClamp10 software (Molecular Devices).

Whole-cell patch-clamp recordings. Slices of $\sim 300-350 \mu \mathrm{m}$ thick were used for whole-cell patch-clamp studies in a submerged chamber perfused at a rate of $1 \mathrm{ml} / \mathrm{min}$ with regular ACSF. Patch clamp of neurons was performed under guidance of infrared differential interference contrast (IR-DIC) optics using an Axopatch 200B patch amplifier (Molecular Devices) with a glass pipette filled with an internal solution containing (in mM) 120 potassium gluconate (KGluc), $2 \mathrm{NaCl}, 5 \mathrm{MgATP}, 0.3$ $\mathrm{Na}_{2} \mathrm{GTP}, 20 \mathrm{KCl}, 10 \mathrm{HEPES}, 1 \mathrm{EGTA}$, and 11.3 D-glucose, with $\mathrm{pH} \sim 7.2-$
7.3 and osmolarity of $\sim 270-280 \mathrm{mOsm}$. Resting membrane potentials (RMPs) were obtained immediately after break-in under current-clamp configuration. Series resistances ranging from 7 to $40 \mathrm{M} \Omega$ were not compensated for during recordings but were monitored throughout the experiments. Recordings were discarded when a significant $(>20 \%)$ change of series resistance was detected. Whole-cell capacitance was obtained by canceling transients when clamping the cell at $-70 \mathrm{mV}$ and applying $5 \mathrm{mV}$ hyperpolarizing pulses for $30 \mathrm{~ms}$. After adjusting the membrane potential to $-70 \mathrm{mV}$, firing properties of neurons and h-current were tested with 11 current injections of $500 \mathrm{~ms}$ duration at intensities ranging from -150 to $+350 \mathrm{pA}$, with $50 \mathrm{pA}$ increments. The threshold firing potential was determined by the lowest membrane potential needed to elicit the first action potential during this current injection process.

To detect the amount of membrane depolarization by nicotine, recordings were performed under the current-clamp configuration in the presence of tetrodotoxin (TTX; $1 \mu \mathrm{M})$ and atropine $(10 \mu \mathrm{M})$. Current was injected into neurons to maintain a membrane potential of $-80 \mathrm{mV}$ at the beginning of the experiment and was kept constant after initiation of recordings. For recordings of postsynaptic events in neurons in layer $\mathrm{V}$ of the EC (ECV neurons), KGluc in the internal solution was replaced with the same concentration of $\mathrm{KCl}$ [for spontaneous IPSC (sIPSC)] or CsGluc [for spontaneous EPSC (sEPSC)]; glucose was replaced with QX314 $(10 \mathrm{~mm})$. All membrane potentials reported here were values after adjustment of liquid junction potentials experimentally tested for each type of internal solution ( $10 \mathrm{mV}$ for internal solutions with KGluc and CsGluc, 4 $\mathrm{mV}$ for internal solution with $\mathrm{KCl}$ ). Signals were passed through a $1 \mathrm{kHz}$ low-pass filter, digitized with the Digidata 1322A (Molecular Devices), and acquired at $10 \mathrm{kHz}$ with pClamp10 software (MDS Analytical Technologies) in all experiments, except in nicotine bath-application experiments in which recordings were acquired at $10 \mathrm{~Hz}$ to reduce data file size.

Determination of functional $n A C h R s$ in neurons. At 5-15 min after break-in during whole-cell recordings, nAChR-mediated responses were evoked by pressure applications ( $350 \mathrm{~ms}, 25$ psi unless indicated otherwise) of maximal doses of either choline (100 mM) or ACh (4 mM) at a 2 min interval through the tip $(0.5-1 \mu \mathrm{m}$ diameter) of a theta style doublebarrel borosilicate glass (outer diameter, $2.0 \mathrm{~mm}$; inner diameter, 1.4 $\mathrm{mm}$; Warner Instruments) located $\sim 30-50 \mu \mathrm{m}$ away from the soma of the targeted neuron. Pressure applications used a PPM-2 pneumatic pump (Harvard Apparatus). To minimize desensitization of nAChRs by agonists leaking from the pipette tip between applications, the pipette was manually placed at the targeted position $5-10 \mathrm{~s}$ before pressure application of either ACh or choline and was retracted by $>200 \mu \mathrm{m}$ away from the neuron immediately after pressure application [this technique was modified from Pidoplichko and Dani (2005)]. This was done under visual guidance of live IR-DIC imaging, and the targeted position was marked to insure that subsequent pressure applications were at the same location. TTX $(1 \mu \mathrm{M})$ and atropine $(10 \mu \mathrm{M})$ were added to the perfusion ACSF in all experiments. Functional $\alpha 7$-containing nAChR ( $\alpha 7 \mathrm{nAChR})$ current responses were assessed by the amplitude of responses to choline, and the peak of non- $\alpha 7$ current responses were determined from responses to ACh in the presence of methyllycaconitine (MLA) (10 nM) to block $\alpha 7$ nAChR-mediated responses; sometimes MLA was omitted when there was no sign of fast activating and desensitizing $\alpha 7$ responses. Using this protocol, the functional $\alpha 7$ current responses induced by the choline (100 $\mathrm{mm}$ ) applications shown here were not significantly different from those induced by ACh (4 mM) applications (in the presence of $1 \mu \mathrm{M}$ dihydro- $\beta$-erythroidine $(\mathrm{DH} \beta \mathrm{E})$ in addition to the abovementioned atropine and TTX) either in amplitude or $10-90 \%$ rise time in CA1 interneurons $(n=9 ; p>0.1$, Student's $t$ test $)$.

Determination of nicotine effects on Sb-ECVI synaptic plasticity. Synaptic plasticity of $\mathrm{Sb}$ input to ECVI pyramidal neurons was tested with whole-cell recordings in ECVI neurons with a KGluc-based internal solution using a stimulating electrode (same as used above) placed in the $\mathrm{Sb}$ area near the $\mathrm{CA} 1$ region. The stimulation intensity was adjusted to evoke a postsynaptic current of $\sim 50 \mathrm{pA}$, and the intensity was usually $\sim 0.5-5$ $\mathrm{mA}$ for $0.1 \mathrm{~ms}$. Short-term potentiation (STP), defined as synaptic potentiation for a few seconds or minutes, often 10-15 min (Sajikumar et al., 2009), was induced by a $100 \mathrm{~ms}$ train of stimulation at $100 \mathrm{~Hz}$. Local 
continuous nicotine exposure was achieved by placing a glass puffer pipette 25-50 $\mu \mathrm{m}$ away from the cell body with continuous pressure of 1-2 psi. To elicit EPSCs in CA1 pyramidal neurons, the Schaffer collateral pathway was stimulated with a 0.1 -ms-duration pulse, with the stimulation intensity adjusted to $50-200 \mu \mathrm{A}$ to evoke EPSCs of 50-100 pA in amplitude. The same type of stimulation was used to obtain the pairedpulse ratio (PPR), which was defined as the ratio of responses evoked by the second versus the first stimulation at an interstimulation interval of $20 \mathrm{~ms}$.

Conventional and confocal imaging. The soma sizes of neurons were determined under IR-DIC optics before patch clamping. The longest axis of each neuron and the axis perpendicular to the longest axis were measured, and the square root of the product of these two values was used to represent its soma diameter. Major dendrites were also counted to help in the determination of whether a neuron was a pyramidal or multipolar neuron. To further visualize the dendritic structures of neurons studied, $5 \mu \mathrm{M}$ Alexa Fluor 488 hydrazide (Alexa488) was added to the patch pipette solution to replace D-glucose. Fluorescence-labeled neurons were imaged with either a cascade digital camera (Roper Scientific) with Andor iQ 1.8 imaging software (Andor Bioimaging Division) or a confocal imaging system (Radiance 2100; Bio-Rad).

Data analysis. Imaging data were acquired and analyzed with BVAnalyze software (BrainVision). The raw data were filtered with spatial $(5 \times 5)$ and cubic $(3 \times 3)$ filters, and baseline drift was removed using the built-in, two-dimensional drift-removal function with a fitting period that ensures maximum stability of the control recording. Preliminary experiments found that during $30 \mathrm{~min}$ of image acquisition, drift of the fluorescence signal during the first $5 \mathrm{~min}$ of imaging did not fit this two-dimensional function and was therefore disregarded before analysis. More than 10 min of control recordings were obtained before drug addition to ensure $\geq 5 \mathrm{~min}$ of control recordings for drift removal.

To compare differences in current or voltage responses mediated by functional nAChRs, values from the different neuronal groups were first tested for a Gaussian distribution $[p>0.1$, Kolmogorov-Smirnov (KS) normality test]. One-way ANOVA and the post hoc Dunnet's test were used to compare Gaussian distribution values, whereas Kruskal-Wallis nonparametric one-way ANOVA with post hoc Dunn's test was used for the others. All the above analyses were performed using Prism 4.03 software (GraphPad Software).

sEPSC and sIPSC events acquired with pClamp10 software were analyzed using MiniAnalysis software (version 6.03; Synaptosoft). Events were initially detected by the software with an amplitude threshold of 5 pA and then were manually examined to exclude false events. Kinetics (10-90\% rise time and decay constant) of sEPSCs, sIPSCs, and AChevoked current responses were also analyzed with MiniAnalysis software. Decay time constants were derived from exponential fits of the $90 \%$ decay responses. KS tests were conducted using MiniAnalysis software. One-way ANOVA and post hoc analysis, dose-response curve $\left(\mathrm{EC}_{50}\right)$ analysis, and normality tests were performed using Prism 4.03 software (GraphPad Software). All values were presented as mean \pm SEM unless noted otherwise.

Drugs and chemicals. TTX was obtained from Tocris. Di-4-ANEPPS, FM 1-43, and Alexa488 were obtained from Invitrogen. All other chemicals or drugs were obtained from Sigma.

\section{Results}

Nicotine depolarizes deep layers of the EC and Sb through the activation of non- $\alpha 7 \mathrm{nAChRs}$ in Wistar rats

VSDI provides high temporal and spatial resolution in monitoring membrane potential changes in neuronal populations in brain slices or under the surface of intact brains (Ebner and Chen, 1995; Airan et al., 2007). Di-4-ANEPPS, a styryl dye that linearly reflects membrane potential changes at a rate of $1 \%$ per $10 \mathrm{mV}$ under physiological conditions (Loew et al., 1992), has been found to reliably detect neuronal membrane potential changes within milliseconds (Mann et al., 2005; Airan et al., 2007). The voltage sensitivity of Di-4-ANEPPS was verified in our experimental set-up (Fig. 1) by fluorescent responses to Schaffer collat- eral stimulation in rat CA1 hippocampal slices stained with this dye, as well as the absence of fluorescent responses in slices stained with the voltage-insensitive dye FM 1-43 (which was used as a control) (Fig. $1 \mathrm{~B}$ ). As reported previously (Tominaga et al., 2000), we also observed significant fluorescence drift (likely caused by photobleaching and other factors) in our slice recordings during $30 \mathrm{~min}$ of imaging, which was accounted for and removed (to obtain a stable VSDI signal baseline) by using a two-dimensional drift-removal function in the BV-Analysis software (Fig. 1C).

After adding TTX $(1 \mu \mathrm{M})$ to remove action potential-dependent synaptic transmission between neurons, we found that bathapplied nicotine $(10 \mu \mathrm{M})$ significantly depolarized neuronal populations in ECVI and stratum oriens of the Sb (SbSO), whereas other regions were depolarized to a lesser extent (Fig. 2).

The two major subgroups of nAChRs in hippocampal neurons are the $\alpha 7$-containing $\mathrm{nAChRs} \mathrm{(} \alpha 7 \mathrm{nAChRs)}$ and a diverse subgroup of non- $\alpha 7 \mathrm{nAChRs}$, the most prevalent of which is the $\alpha 4 \beta 2$ subtype in the hippocampus and cortex (Alkondon and Albuquerque, 1993; Alkondon et al., 1994; Jones and Yakel, 1997; Sudweeks and Yakel, 2000). We found that the non- $\alpha 7 \mathrm{nAChR}$ antagonist $\mathrm{DH} \beta \mathrm{E}(1 \mu \mathrm{M})$ blocked nicotine-induced VSDI responses, whereas the $\alpha 7 \mathrm{nAChR}$-selective antagonist MLA (10 $\mathrm{nm}$ ) did not (Fig. $2 A, C$ ), which demonstrates that the nicotineinduced neuronal depolarizations were mediated by non- $\alpha 7$ nAChRs. The viability of neurons in slices was verified by the ability of $4 \mathrm{~mm} \mathrm{KCl}$ to induce significant depolarization (Fig. $1 D, 2 A)$ or, in some cases, by Schaffer collateral stimulationevoked responses recorded through field electrodes (Fig. 1B). Brain slices stained with the voltage-insensitive dye FM 1-43 did not show any fluorescent responses to nicotine $(10 \mu \mathrm{M})$ (Fig. 2A), which suggests that nicotine-induced fluorescent responses using Di-4-ANEPPS were not attributable to some interaction between nicotine and the fluorescent dye (independent of membrane potential changes), the influence of nicotine on slice optical characteristics, or any potential membrane surface change as a result of synaptic vesicle release triggered by nicotine.

\section{Layer ECVI neurons are the most responsive to nicotine}

We used whole-cell patch-clamp techniques to record from individual neurons within various regions and layers of the HF (Fig. $3 A$ ) to directly measure the ability of nicotine to induce electrical responses and how this pattern of responsiveness compared with the VSDI results. Under current clamp, we found that all ECVI neurons that we recorded from $(n=26)$ were depolarized by bath-applied nicotine $(10 \mu \mathrm{M})$ (Table 1, Fig. 3) and that the amount of depolarization was larger compared with neurons in other regions of the HF (Fig. $3 B, C$ ).

To compare the kinetics of the nicotine-induced depolarizations in different regions of the HF, we averaged the membrane potential recordings in response to nicotine (Fig. $3 B$ ). We found that the depolarizations induced by the bath application of nicotine for $5 \mathrm{~min}$ reached peak within $1 \mathrm{~min}$ and then slowly repolarized back to baseline. The repolarizations were caused by the decay of nicotine responses (most likely as a result of desensitization) and not as a result of membrane potential drift since the nicotine responses were completely blocked (i.e., complete recovery of membrane potential to the value before nicotine application) by $\mathrm{DH} \beta \mathrm{E}$ (either 1 or $100 \mu \mathrm{M}$ for complete inhibition). The decay rate (i.e., the percentage of decay after $5 \mathrm{~min}$ of nicotine application) in the CA1 stratum radiatum (SR) neurons $(17 \pm 6 \% ; n=4)$ was similar to that in ECVI neurons $(15 \pm 4 \% ; n=16)$, both of which were significantly slower than that in the SbSO neurons $(57 \pm 6 \% ; n=9)$ or 
A

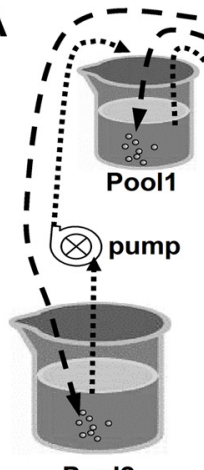

Pool2

B
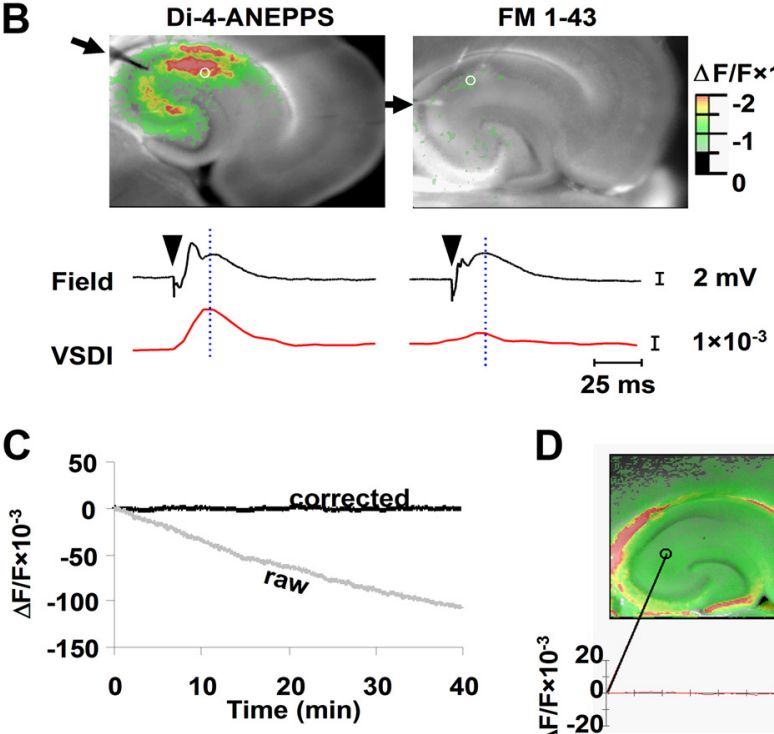

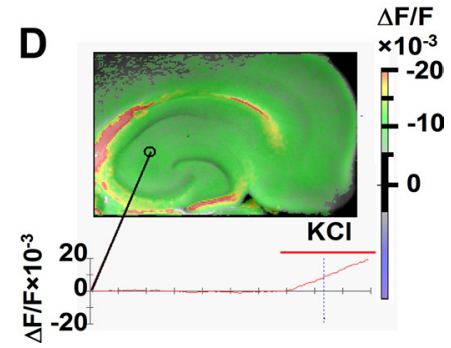

Figure 1. VSDI set-up and control experiments. $A$, VSDI set-up. A stained slice was placed in an interface chamber. The liquid level of the perfusion source (Pool1) was stabilized by refilling solution through a pump from another ACSF pool ( $\mathrm{Pool}$ 2) at the same rate as bath perfusion. A THT microscope and MiCAM02 camera system were used to record fluorescent images using an excitation filter (ex), a dichroic mirror (dic), an emission filter (em), an objective lens (obj), and a projection lens (pro). Drugs desired for bath application were added to both pools simultaneously. In some experiments, a stimulation electrode (Stim) and a field (Field) recording electrode were also introduced. B, Stimulation-evoked responses are shown in slices stained with Di-4-ANEPPS (left) or FM 1-43 (right), confirming the voltage sensitivity of Di-4-ANEPPS. Colored pixels represent fluorescent changes at levels indicated in the legend on the right. Single $0.1 \mathrm{~ms}, 400 \mu$ A stimulation was delivered to Schaffer collateral fibers through a bipolar electrode (arrows) to evoke neuronal depolarization responses. Field recordings and VSDI signals (traces below each image) at a spot in CA1 stratum radiatum (white circle) demonstrated that VSDI signals corresponded well with field potentials in the Di-4-ANEPPSstained slice. The arrowheads above traces indicate time of stimulation, and the vertical blue dotted line indicates the time when the displayed images were taken. Images and traces are averages of 10 stimulation trials. C, Drifting of VSDI signals at a spot in the deep EC area $(3 \times 3$ pixel area) during 40 min of imaging in slices perfused with ACSF. After correction of drifting using a two-dimensional function in BV-Analyze software, imaging signals showed a stable baseline at a low noise level (root mean square, $0.1 \%)$. D, A VSDI image of a TTX-treated slice after $5 \mathrm{~min}$ of $\mathrm{KCl}(4 \mathrm{~mm})$ bath application. The trace below the image shows VSDI signal values over time at the indicated spot $(3 \times 3$ pixels). The VSDI baseline signal was stable during 20 min of perfusion, and significant fluorescent responses were induced by bath addition of KCI ( $4 \mathrm{mM})$.

ECV neurons $(43 \pm 8 \% ; n=8)(p<0.01$, one-way ANOVA followed by the Newman-Keuls multiple comparison test). When $\mathrm{DH} \beta \mathrm{E}$ was replaced by the ionotropic glutamatergic receptor blockers 2,3-dioxo-6-nitro-1,2,3,4-tetrahydrobenzo[f] quinoxaline-7- sulfonoamide (NBQX; $20 \mu \mathrm{M})$ and APV $(50 \mu \mathrm{M})$, the nicotine-induced responses in ECVI neurons were not affected ( $n=3$; data not shown), precluding the contribution of glutamate release to the nicotine-induced depolarization.

The concentration of nicotine required to produce halfmaximal depolarizations (i.e., the $\mathrm{EC}_{50}$ value) was $0.6 \mu \mathrm{M}$ for ECVI neurons (Fig. 3D), which was significantly lower than for either SbSO $(1.3 \mu \mathrm{M})$ or ECV $(5.5 \mu \mathrm{M})$ neurons $(p<0.01$, two- way ANOVA using concentration and region as variables followed by Bonferroni posttests). The bath application of a low concentration of nicotine $(0.1 \mu \mathrm{M})$, which is within the range found in the blood of average smokers (i.e., $0.06-0.31 \mu \mathrm{M}$ ) (Moriya and Hashimoto, 2004; Hukkanen et al., 2005; Moriya et al., 2006), still significantly depolarized ECVI neurons, unlike either SbSO or ECV neurons (Fig. 3B).

\section{Functional distribution of $\mathrm{nAChR}$ - mediated current responses in the $\mathrm{HF}$} We recorded nAChR-mediated current responses under voltage clamp during the rapid pressure application of $\mathrm{ACh}$ to the soma of neurons in different regions of the HF in the presence of TTX $(1 \mu \mathrm{M})$ and atropine $(10 \mu \mathrm{M})$. Under these conditions, there will be little to no desensitization of nAChR-mediated responses, which is particularly important for $\alpha 7 \mathrm{nAChRs}$ that are characterized by rapid desensitization (Jones and Yakel, 1997; McQuiston and Madison, 1999; Alkondon and Albuquerque, 2002; Khiroug et al., 2003). To isolate the non- $\alpha 7 \mathrm{nAChR}$-mediated current responses, we activated responses with ACh in the presence of MLA (10 nM), and to isolate the $\alpha 7 \mathrm{nAChR}$ component, we activated responses with the full $\alpha 7$ nAChR-selective agonist choline (Fig. 4A). Although MLA has previously been reported to block $\alpha 6$-containing nAChRs (Klink et al., 2001), the $\alpha 6$ subunit is not expressed in rat hippocampus and EC (Sudweeks and Yakel, 2000; Mugnaini et al., 2002), and thus this should not affect the interpretation of our results. We found that ECVI and SbSO neurons had the largest non- $\alpha 7$ nAChR-mediated responses (Fig. $4 B$, Table 1), similar to what we observed for nicotine-induced depolarizations. These data indicate that ECVI and SbSO neurons had the highest levels of functionally expressed non- $\alpha 7 \mathrm{nAChRs,}$ which is consistent with the previous VSDI results that ECVI and SbSO were the most nicotine-responsive regions in the HF.

After blocking $\alpha 7 \mathrm{nAChRs}$ with MLA (10 nM), the bath application of $\mathrm{DH} \beta \mathrm{E}(1 \mu \mathrm{M})$ blocked $>95 \%$ of the nicotine-induced depolarizations in neurons of the ECVI (median, $96.6 \%$; interquartile range, $83.3-99.3 \% ; n=15)$, the SbSO $(98.3 \% ; 96.0-$ $98.9 \% ; n=5)$, and the CA1 SR $(98.3 \%$; $94.3-99.1 \% ; n=11)$. The $\alpha 4 \beta 2$ nAChR subtype, besides being the most prevalent subtype in the hippocampus and cortex, has the highest affinity for nicotine and DH $\beta E$ (Harvey et al., 1996; Marks et al., 1999). The pharmacological data for our non- $\alpha 7$ nAChR-mediated responses are most consistent with their being composed mostly of the $\alpha 4 \beta 2$ subtype, and not consistent with the other common subtypes of non- $\alpha 7$ nAChRs expressed in the brain (e.g., the 



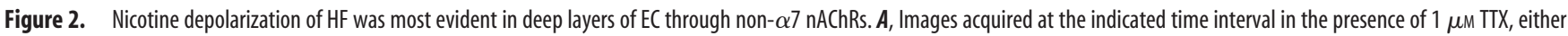
without nicotine bath perfusion (first row) or with $10 \mu \mathrm{m}$ nicotine (Nic; the rest of the rows). The nicotine-induced VSDI signals were not blocked by preperfusion of the $\alpha 7 \mathrm{nAChR}$ antagonist MLA ( $10 \mathrm{~nm}$; third row) but by the non- $\alpha 7 \mathrm{nAChR}$ antagonist $\mathrm{DH} \beta \mathrm{E}$ ( $1 \mu \mathrm{m}$; fourth row). An additional $4 \mathrm{~mm} \mathrm{KCl}$ application induced depolarization in slices when nicotine effects were blocked by $\mathrm{DH} \beta \mathrm{E}$ (fourth row), confirming the viability of the slices. The last row shows a slice stained with FM 1-43 (a nonvoltage-sensitive dye), which failed to induce detectable fluorescence changes after nicotine application. The figure legend (top right) indicates values of fluorescence change corresponding to the color of pixels. Any pixel with a fluorescence change below $0.25 \%$ was left transparent so that a gray-scale background image of the slice could be shown to indicate the location of voltage changes. $\boldsymbol{B}$, Activation map of nicotine effect in TTX-treated slices show a sequence of nicotine-induced depolarization (images derived from the same slice as the third row in $A$ ). Colored pixels indicate areas depolarized at 2 min (green), 3 min (brown) and 4 min (red) after bath application of nicotine $(10 \mu \mathrm{M})$. The map was derived after smoothing with a $9 \times 9$ spatial filter. The nicotine-induced depolarization started in ECVI and part of SbSO at 2 min and then extended to neighboring regions at 3 and $4 \mathrm{~min}$. Colored areas are regions above a threshold of $0.25 \%$ fluorescent change. PRh, Pararhinal cortex; 50 , stratum oriens; sr, stratum radiatum; slm, striatum lacunosum moleculare; Den, dentate; PaSb, parasubiculum; PrSb, presubiculum. C, Averages of fluorescent changes in ECVI induced by bath application of nicotine (Nic; $10 \mu \mathrm{m}$ ) in the presence of TTX (1 $\mu \mathrm{m} ;$ red line; $n=8$ ), TTX and MLA (10 nм; blue line; $n=5)$, or TTX and DH $\beta$ E (1 $\mu \mathrm{m}$; green line; $n=6)$. Error bars indicate SEM.

$\alpha 3 \beta 4$ subtype) (Jones and Yakel, 1997; Sudweeks and Yakel, 2000). Neither the $\alpha 3$ nor the $\alpha 2$ nAChR subunits were previously detected in the deep layers of the EC, whereas the $\alpha 4$ and $\beta 2$ subunits were (Wada et al., 1989), as well as the lack of presence of the $\alpha 6 \mathrm{nAChR}$ subunit.

The functional distribution of $\alpha 7 \mathrm{nAChR}$-mediated current responses (i.e., those responses activated by choline) is shown in Figure $4 B$ and Table 1. Interestingly, most ECVI neurons (89\%) had functional $\alpha 7$ responses with a median amplitude not significantly different from CA1 interneurons $(p>0.05$, KruskalWallis test and post hoc Dunn's multiple comparison test). Since $\alpha 7 \mathrm{nAChRs}$ desensitize rapidly, the most likely reason why we did not observe an $\alpha 7$ receptor-mediated depolarizing component in response to bath-applied nicotine in ECVI neurons was because of desensitization. To address this point directly, we used the $\alpha 7$-selective allosteric potentiator PNU-120596 (PNU), which dramatically increases $\alpha 7$ response amplitudes in part by reducing desensitization (Hurst et al., 2005; Poisik et al., 2008). Bath application of nicotine (under current clamp; $n=3$ ) to CA1 SR interneurons that functionally expressed only $\alpha 7 \mathrm{nAChRs}$ (and not non- $\alpha 7 \mathrm{nAChRs)}$ failed to induce any membrane depolarization (Fig. 5). However after the application of PNU (10 $\mu \mathrm{M}$; to other $\alpha 7$-only CA1 SR interneurons), the bath application of nicotine was now able to induce significant membrane depolarizations (Fig. 5) $(n=3)$. These results demonstrate that desensitization prevented $\alpha 7 \mathrm{nAChRs}$ from contributing to the neuronal depolarization induced by the bath application of nicotine under physiological conditions.

The $\alpha 7$-only nature of these responses was verified by similar (defined as $<5 \%$ difference) rise and decay kinetics be- 
A
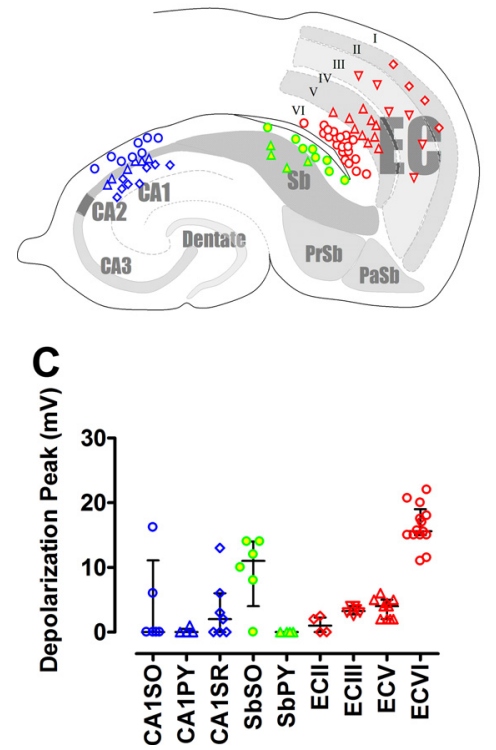

B

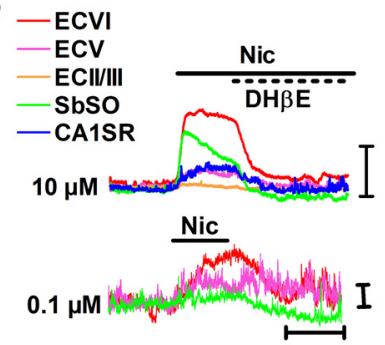

D

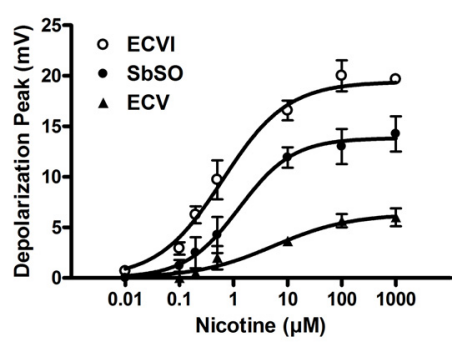

Figure 3. Patch-clamp recordings confirm ECVI neurons as the most nicotine-sensitive neuronal population in the HF. $\boldsymbol{A}$, Approximate locations of individual neurons studied for nicotine-induced (bath-application) depolarizations with whole-cell current clamp in the presence of $1 \mu \mathrm{M}$ TTX. PaSb, Parasubiculum; PrSb, presubiculum. $\boldsymbol{B}$, Top traces show averaged membrane potential recordings obtained from neurons in selected regions as indicated in $A$. Because of the irresponsiveness of some neurons in the CA1 SR region, traces from four of seven CA1 SR neurons that responded to nicotine (Nic) with $>1 \mathrm{mV}$ depolarization were averaged and shown; this was done so that the time course of the nicotine effect was more evident. Depolarizations by nicotine (10 $\mu \mathrm{M})$ in all neurons were mostly blocked by $\mathrm{DH} \beta \mathrm{E}(1 \mu \mathrm{M})$, and $\mathrm{ECVI}$ neurons had the largest amplitude of responses among the regions studied. The bottom traces are averaged membrane potential recordings from five neurons in each specified region during 5 min of bath application with a lower concentration of nicotine $(0.1 \mu \mathrm{m})$. Note that this lower concentration of nicotine $(0.1 \mu \mathrm{m})$ significantly induced depolarization in neurons of $\operatorname{ECVI}(n=6 ; p<0.05$, Student's $t$ test on peak values compared with the control recordings without nicotine application) but not in those of either SbSO or ECV ( $n=5 ; p>0.05)$. Calibration: vertical, $10 \mathrm{mV}$ (top traces) and $1 \mathrm{mV}$ (bottom traces); horizontal, $5 \mathrm{~min}$. C, Peaks of membrane depolarization induced by nicotine (10 $\mu \mathrm{m})$ in neurons shown in $\boldsymbol{A}$. Each data point represents data from one neuron, and the error bars are medians with interquartile ranges. ECVI neurons had significantly more depolarization compared with the other regions ( $p<0.05$, Student's $t$ test to compare ECVI and SbSO values since they are normally distributed; the nonparametric Kruskal-Wallis test followed by the Dunn's multiple comparison test were used to compare the rest). CA1PY, CA1 pyramidal layer; SbPY, Sb pyramidal layer. D, Dose-response curves demonstrate that neurons in ECVI were the most sensitive to nicotine. Data points represent averages of peak responses in at least three neurons. Error bars represent SEM.

tween responses to ACh and the full and selective $\alpha 7 \mathrm{nAChR}$ agonist choline, and the significantly slower kinetics of non- $\alpha 7$ nAChRs. The absence of non- $\alpha 7 \mathrm{nAChR}$-mediated currents in these $\alpha 7$-only neurons was further confirmed by the lack of changes in the kinetics of responses to ACh after the bath application of $\mathrm{DH} \beta \mathrm{E}(1 \mu \mathrm{M})$. As a final confirmation, $21 \alpha 7$-only neurons were selected from 68 CA1 SR neurons using these criteria, and ACh-evoked currents in all of these neurons were completely (>95\%) blocked by 10 nM MLA.

\section{Characteristics of ECVI neurons}

We characterized the morphological and electrical properties of ECVI neurons, which were usually referred to as part of the deep layers of the EC along with ECV neurons (Chrobak and Buzsaki, 1994; Solger et al., 2004; Gnatkovsky and de Curtis, 2006).

\section{Morphological properties of ECVI neurons}

As reported previously (Dugladze et al., 2001), the shapes of ECVI neurons may be either pyramidal or multipolar, whereas ECV neurons are primarily pyramidal shaped. When observed under IR-DIC optics, the soma diameters of ECVI neurons were not significantly different from CA1 interneurons but were significantly larger than the diameters of either ECV or CA1 pyramidal neurons (Table 2). The measurements of neuronal size under IR-DIC are consistent with a previous report (Ruan et al., 2007). The membrane capacitance (an indicator of membrane surface area) of ECVI neurons was significantly larger than CA1 neurons, suggesting that ECVI neurons had more dendritic arboration than CA1 neurons since their soma sizes were similar.

\section{Electrical properties of ECVI neurons}

The RMPs of ECVI neurons were more negative than those of CA1, Sb, ECII, or ECVIII neurons (Table 2). In addition, the ECVI neurons had the lowest level of h-current $\left(I_{h}\right)$ among all regions of neurons studied. $I_{\mathrm{h}}$ is a current mediated by a hyperpolarization-activated cyclic nucleotide-gated (HCN) channel (Rosenbaum and Gordon, 2004; Siu et al., 2006). Although HCN channels are weakly selective for $\mathrm{K}^{+}$over $\mathrm{Na}^{+}$with permeability ratios of $\sim 4: 1$, under physiological conditions, $I_{\mathrm{h}}$ is mostly carried by $\mathrm{Na}^{+}$because of a greater driving force (Siu et al., 2006). $I_{\mathrm{h}}$ has a significant impact on the RMP since inhibition of $I_{\mathrm{h}}$ hyperpolarizes neurons (Lupica et al., 2001; Aponte et al., 2006). Therefore, a low $I_{\mathrm{h}}$ amplitude, such as that found in ECVI neurons, can contribute to the more hyperpolarized RMP of these neurons. The ECVI neurons also had smaller input resistances than CA1 interneurons, spiked at a frequency slower than CA1 interneurons but faster than CA1 pyramidal neurons when depolarized (i.e., medium frequency spiking), and had similar action potential thresholds (Table 2).

\section{ECVI neurons provide both excitatory} and inhibitory inputs to ECV neurons

Both ECVI and ECV neurons project mainly to superficial layers of the EC (Kohler, 1986; Dolorfo and Amaral, 1998; Hamam et al., 2000) and a wide range of cortical areas including the temporal pole, medial frontal and orbitofrontal cortices, and the rostral part of the polysensory area of the superior temporal sulcus cortices (Wyss and Van Groen, 1992; Deller et al., 1996; Hamam et al., 2000; Munoz and Insausti, 2005). Through these projections, ECVI and ECV neurons may impact indirectly on hippocampal functions since the neurons in superficial layers of the EC (ECII or ECIII) are the major sources of inputs received by the dentate and the hippocampal proper. Projections from ECVI or ECV were also identified targeting neurons in the $\mathrm{Sb}$ and the dentate gyrus directly (Dugladze et al., 2001), suggesting that direct influence on hippocampal function by deep EC neurons is also possible. We found that ECVI neurons, which are mainly excitatory neurons (Hamam et al., 2000), were the most responsive to nicotine (based on the VSDI and patch-clamp experiments described above). Thus far, there are no reports demonstrating the functional synaptic influence of the neuronal activation of ECVI on neurons in other regions. Because the ECV neurons are the closest neuronal population to the ECVI region, any connection between ECV and ECVI neurons may be well preserved in the 
Table 1. Comparing nAChR-mediated responses in ECVI neurons with those in other regions

\begin{tabular}{|c|c|c|c|c|c|c|c|c|c|c|}
\hline Activation & CA1SO & CA1PY & CA1SR & CA1SLM & SbSO & SbPY & $\mathrm{ECll}$ & ECIII & ECV & $\mathrm{ECVI}$ \\
\hline \multicolumn{11}{|l|}{ Bath } \\
\hline Percentage & $33 \%(2 / 6)$ & $25 \%(1 / 4)$ & $57 \%(4 / 7)$ & $* *$ & $92 \%(12 / 13)$ & $0 \%(0 / 4)$ & $50 \%(2 / 4)$ & $100 \%(6 / 6)$ & $89 \%(16 / 18)$ & $100 \%(26 / 26)$ \\
\hline$\Delta V_{\mathrm{m}}(\mathrm{mV})$ & $0(0-11)$ & $0^{*}(0-1)$ & $2^{\dagger *}(0-6)$ & $* *$ & $11^{\dagger *}(4-14)$ & $0(0-0)$ & $1^{\dagger *}(0-2)$ & $3^{\dagger *}(3-4)$ & $4^{\dagger *}(2-5)$ & $16^{\dagger}(15-19)$ \\
\hline \multicolumn{11}{|l|}{ Non- $\alpha 7$} \\
\hline Percentage & $41 \%(11 / 27)$ & $33 \%(8 / 24)$ & $45 \%(49 / 109)$ & $46 \%(6 / 13)$ & $92 \%$ & $0 \%(0 / 4)$ & $89 \%$ & $100 \%$ & $75 \%$ & $100 \%(6 / 6)$ \\
\hline$I_{\text {peak }}(\mathrm{pA})$ & $0^{*}(0-80)$ & $0^{*}(0-13)$ & $4^{*}(0-24)$ & $0^{*}(0-31)$ & $110^{\dagger}(68-170)$ & $0^{*}(0-3)$ & $14^{t_{*}}(5-29)$ & $53^{\dagger *}(48-88)$ & $33^{\dagger *}(18-50)$ & $123^{\dagger}(70-188)$ \\
\hline Percentage & $75 \%(21 / 28)$ & $23 \%(6 / 26)$ & $77 \%(106 / 138)$ & $84 \%(16 / 19)$ & $54 \%(7 / 13)$ & $0 \%(0 / 4)$ & $75 \%(3 / 4)$ & $17 \%(1 / 6)$ & $33 \%(6 / 18)$ & $89 \%(25 / 28)$ \\
\hline$I_{\text {peak }}(\mathrm{pA})$ & $107(23-340)$ & $0^{*}(0-10)$ & $50(7-132)$ & $70^{\dagger}(24-200)$ & $25(0-65)$ & $0(0-0)$ & $25^{\dagger}(10-55)$ & $0(0-15)$ & $0^{*}(0-30)$ & $38(20-80)$ \\
\hline
\end{tabular}

Data show percentages of neurons tested that had detectable voltage responses (threshold, $1 \mathrm{mV}$ ) and median membrane potential changes $\left(\Delta V_{\mathrm{m}}\right.$ ) when activated by bath application of nicotine (10 $\mu \mathrm{m}$ for $10 \mathrm{~min}$; Bath), or detectable current responses (threshold, $5 \mathrm{pA}$ ) and median peak currents $\left(I_{\text {peak }}\right.$ ) mediated by non- $\alpha 7$ or $\alpha 7 \mathrm{nAChRs}$ tested with ACh or choline local pressure application ( $350 \mathrm{~ms}, 25 \mathrm{psi}$; see Materials and Methods for details). Numbers in parentheses indicate the number of responsive neurons over the total tested; ranges in parentheses represent the 25 th and 75 th percentiles. ${ }^{* *}$ Value not tested for function nAChR currents. ${ }^{\dagger}$ Values with Gaussian distribution ( $p>0.1$, KS normality test) *Values significantly different from those of ECVI neurons ( $p<0.05$, one-way ANOVA and post hoc Dunnet's test for comparison between Gaussian distribution values, Kruskal-Wallis nonparametric one-way ANOVA post hoc Dunn's test for the others). CA1S0, CA1 stratum oriens; CA1PY, CA1 pyramidal layer; CA1SLM, CA1 stratum lacunosum moleculare; SbPY, Sb pyramidal layer.

A

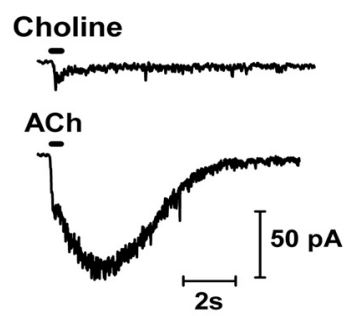

B


Figure 4. Functional distribution of $\alpha 7$ and non- $\alpha 7$ nAChRs in the HF. $A$, An ECVI neuron demonstrated a rapidly activating and desensitizing $\alpha 7 \mathrm{nAChR}$-mediated current in response to the local application of choline (top trace) and a mixture of fast ( $\alpha 7 \mathrm{nAChR}$ mediated) and slow (non- $\alpha 7 \mathrm{nAChR}$ mediated) desensitizing current evoked by the local application of ACh (bottom trace). $\boldsymbol{B}$, Scatter plots of functional $\alpha 7$ (top) and non- $\alpha 7$ (bottom) nAChR-mediated currents evoked by local application to neurons in the various regions. Significantly larger non- $\alpha 7$ nAChR-mediated currents were found in ECVI and SbSO neurons than CA1 neurons. Each data point represents the value from an individual neuron, and the error bars are median and interquartile ranges (see Table 1 for statistical analysis; see Materials and Methods for isolation of $\alpha 7$ and non- $\alpha 7 \mathrm{nAChR}$-mediated currents). Please note that the $y$-axis scales of the top segment are different from the bottom segment; this was done to better demonstrate the differences among regions with smaller responses.

hippocampal slices that we have studied. In addition, ECV neurons are known to mediate interactions between the hippocampal proper and a wide range of neocortical areas (Insausti et al., 1997; Naber et al., 2001). Therefore, if ECV neurons were influenced directly by ECVI neurons, nicotine may influence the function of various hippocampal regions through the activation of



PNU

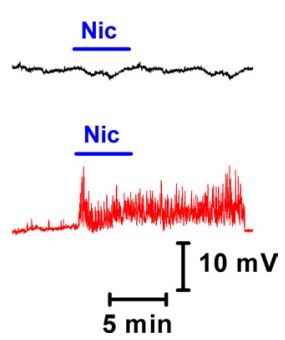

Figure 5. Desensitization prevents $\alpha 7$ nAChRs from contributing to membrane depolarizations induced by the bath application of nicotine. An $\alpha 7$-only neuron responded to the local application ( $5 \mathrm{~s}$ duration) of ACh ( $4 \mathrm{~mm}$ ) with a fast desensitizing current (top left). The bath application of nicotine (Nic; $10 \mu \mathrm{m}$; top right) to this neuron failed to induce a membrane depolarization. A fast-desensitizing current response in another $\alpha 7$-only neuron (black trace; bottom left) was significantly prolonged by PNU (10 $\mu \mathrm{m}$; red traces; bottom left). The bath application of the same concentration of nicotine to this PNU-treated neuron induced a significant depolarization. Experiments were performed in the presence of TTX (1 $\mu \mathrm{M})$, atropine (10 $\mu \mathrm{M})$, and $\mathrm{DH} \beta \mathrm{E}(1 \mu \mathrm{M})$.

neurons in the ECV, which will further influence ECII/III neurons, the major source of inputs for the dentate gyrus.

To investigate whether ECV neurons are postsynaptically activated by ECVI neurons, we recorded spontaneous glutamatergic (Fig. 6) or GABAergic (Fig. 7) postsynaptic currents (sEPSCs and sIPSCs) in ECV neurons with whole-cell voltage-clamp recordings while bath-perfusing the slices with nicotine $(10 \mu \mathrm{M})$, or by locally activating non- $\alpha 7 \mathrm{nAChRs}$ in ECVI neurons and other neighboring regions. Bath-applied nicotine $(10 \mu \mathrm{M})$ significantly increased the frequency of sEPSCs $(n=5)$ (Fig. $6 A, B)$ but not that of sIPSCs $(n=5 ; p>0.05$, KS test) (Fig. $7 A)$ recorded in ECV pyramidal neurons, demonstrating that bath-applied nicotine enhanced excitatory but not inhibitory inputs onto ECV neurons through the activation of non- $\alpha 7$ nAChRs. The brief (350 ms duration) local application of ACh (4 mM; $\sim 200 \mu \mathrm{m}$ away from recorded neurons) to ECVI neurons in the presence of antagonists of muscarinic AChRs (atropine, $10 \mu \mathrm{M}$ ) and $\alpha 7 \mathrm{nAChRs}$ (MLA, $10 \mathrm{nM}$ ) also significantly increased the frequency of sEPSCs onto ECV neurons $(n=5 ; 0.29 \pm 0.08 \mathrm{~Hz}$ in control condition compared with $7.3 \pm 2.0 \mathrm{~Hz}$ within $10 \mathrm{~s}$ after brief local activation of non- $\alpha 7$ nAChRs in ECVI neurons; $p<0.05$, paired $t$ test) (Fig. 6D). This increase did not occur when ACh was locally applied to ECIII or neighboring ECV neurons that were similar distances away from the recorded ECV neuron $(n=5$; $p>0.05$, paired $t$ test), indicating that ECVI neurons act as a major source of excitatory inputs for ECV. 
Table 2. Size and electrophysiological properties of ECVI neurons

\begin{tabular}{|c|c|c|c|c|c|c|c|}
\hline & $C_{m}(\mathrm{pF})$ & $\varnothing(\mu \mathrm{m})$ & $\mathrm{RMP}(\mathrm{mV})$ & $\mathrm{FTP}(\mathrm{mV})$ & $f_{\text {spiking }}(\mathrm{Hz})$ & $R_{\text {input }}(\mathrm{M} \Omega)$ & $I_{\mathrm{h}}(\mathrm{pA})$ \\
\hline CA1SO & $22.6 \pm 1.4(22)^{*}$ & $17.8 \pm 0.6(33)$ & $-62.9 \pm 1.1(32)^{*}$ & $-56.0 \pm 1.4(21)$ & $37.8 \pm 4.9(21)^{*}$ & $376.7 \pm 23.1(28)^{*}$ & $26.4 \pm 3.4(25)^{*}$ \\
\hline CA1PY & $23.5 \pm 2.2(23)^{*}$ & $15.2 \pm 0.4(31)^{*}$ & $-64.8 \pm 0.7(30)^{*}$ & $-55.7 \pm 0.6(26)$ & $17.2 \pm 1.3(26)^{*}$ & $265.1 \pm 27.8(33)$ & $29.2 \pm 1.6(26)^{*}$ \\
\hline CA1PYInt & $19.0 \pm 6.0(2)$ & $15.5 \pm 2.2(2)$ & $-67.7 \pm 1.8(3)$ & $-59.5 \pm 4.5(2)$ & $48.0 \pm 12.0(2)$ & $381.7 \pm 72.4(2)$ & $23.8 \pm 8.8(2)$ \\
\hline CA1SR & $22.7 \pm 0.8(82)^{*}$ & $17.8 \pm 0.2(163)$ & $-62.7 \pm 0.4(146)^{*}$ & $-53.5 \pm 0.3(76)$ & $34.5 \pm 1.1(76)^{*}$ & $409.1 \pm 13.2(137)^{*}$ & $21.9 \pm 1.6(103)^{*}$ \\
\hline CA1SLM & $17.5 \pm 1.9(11)^{*}$ & $17.4 \pm 0.8(18)$ & $-61.8 \pm 1.2(18)^{*}$ & $-54.7 \pm 1.0(6)$ & $41.0 \pm 5.0(6)^{*}$ & $491.4 \pm 52.8(17)^{*}$ & $13.2 \pm 6.8(9)$ \\
\hline SbPY & $37.1 \pm 5.0(7)$ & $17.7 \pm 0.5(7)$ & $-65.8 \pm 0.9(7)$ & $-57.0 \pm 1.8(5)$ & $12.0 \pm 3.9(6)$ & $280.5 \pm 23.8(16)$ & $12.1 \pm 2.3(16)$ \\
\hline SbSO & $34.5 \pm 2.8(16)$ & $17.3 \pm 0.4(14)$ & $-70.6 \pm 1.7(14)^{*}$ & $-54.3 \pm 0.9(15)$ & $20.1 \pm 2.7(15)$ & $134.0 \pm 20.6(8)$ & $24.9 \pm 4.6(6)^{*}$ \\
\hline ECII & $43.9 \pm 5.7(10)$ & $18.5 \pm 0.4(10)$ & $-65.0 \pm 0.3(10)^{*}$ & $-53.3 \pm 0.9(4)$ & $12.5 \pm 3.8(4)$ & $171.5 \pm 36.0(10)$ & $21.0 \pm 3.0(4)$ \\
\hline $\mathrm{ECIII}$ & $35.9 \pm 4.1(14)$ & $17.7 \pm 0.5(14)$ & $-64.7 \pm 1.9(9)^{*}$ & $-57.2 \pm 0.6(6)$ & $16.0 \pm 1.3(6)$ & $168.6 \pm 6.8(14)$ & $12.6 \pm 8.6(4)$ \\
\hline ECV & $26.1 \pm 1.5(38)$ & $14.1 \pm 0.3(36)^{*}$ & $-71.0 \pm 1.1(21)$ & $-54.4 \pm 1.1(31)$ & $17.6 \pm 1.8(31)$ & $289.7 \pm 12.0(42)$ & $12.3 \pm 1.5(33)$ \\
\hline $\mathrm{ECVI}$ & $36.6 \pm 1.5(48)$ & $16.8 \pm 0.3(49)$ & $-73.0 \pm 1.2(34)$ & $-53.2 \pm 0.4(45)$ & $21.5 \pm 0.8(45)$ & $271.9 \pm 8.4(54)$ & $4.3 \pm 0.9(45)$ \\
\hline
\end{tabular}

Data shown are average \pm SEM. Numbers in parentheses were numbers of neurons examined. $C_{m}$, Whole-cell capacitance; $\varnothing$, soma diameter; FTP, firing threshold potential; $f_{\text {spiking, }}$ frequency of spiking evoked by 500 ms, 150 pA depolarization current; $R_{\text {input }}$, input resistance; $I_{h}$, h-current calculated from the voltage sag during $500 \mathrm{~ms}$ of membrane hyperpolarization. *Values significant from ECVI neurons ( $p<0$.05, one-way ANOVA followed by post hoc Dunnet's multiple comparison test). CA1PYInt, CA1 pyramidal layer interneurons. Other abbreviations are the same as in Table 1.

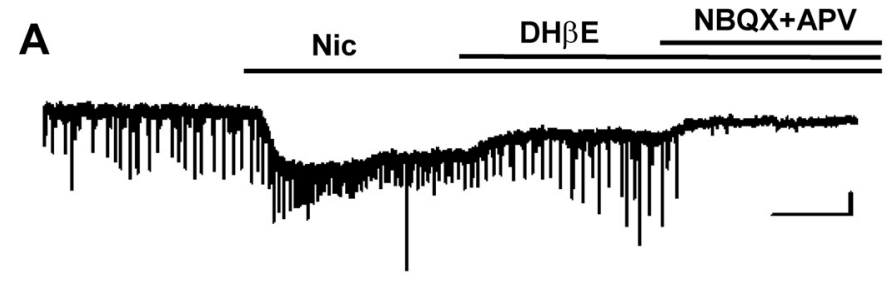

B


Figure 6. Nicotine-sensitive ECVI neurons provide glutamatergic inputs to pyramidal neurons in ECV. $A$, SEPSCS were recorded from an ECV neuron when voltage clamped at $-80 \mathrm{mV}$ with a CsGluc-based internal solution containing QX314. The increase in sEPSC frequency by bath-applied nicotine (Nic; $10 \mu \mathrm{m})$ was reversed by $\mathrm{DH} \beta \mathrm{E}(10 \mu \mathrm{m})$. The recorded ECV neuron also responded to nicotine with a slower inward current response, which was evidenced by a baseline shift after nicotine application. The ionotropic glutamatergic receptor blockers NBQX $(20 \mu \mathrm{m})$ and APV $(25 \mu \mathrm{m})$ were applied at the end of the experiment to verify that the recorded events were mediated by glutamatergic receptors. Calibration: horizontal, 2 min; vertical, 50 pA. $\boldsymbol{B}$, Pooled data from three ECV neurons showed that the cumulative probability of sEPSC intervals significantly decreased between 1 and 5 min after nicotine (Nic) application (red line; $p<0.05$, KS test) and recovered to control levels (black line) between 1 and 5 min after DH $\beta E$ application (blue line; $p>0.05$, KS test). C, To confirm that ECVI neurons were the major source of nicotine-inducible glutamatergic inputs to ECV neurons, ACh (4 mm) was locally applied to neighboring regions of the EC through sharp glass pipettes (tip diameter, $\sim 1 \mu \mathrm{m}$ ), whereas an ECV neuron was recorded under whole-cell voltage clamp. The various locations of ACh application (long arrowheads) are shown. Besides the control location that was set away from the slice, ACh applications were $\sim 180-220$ $\mu \mathrm{m}$ away from the recorded neurons. $\boldsymbol{D}$, In the presence of atropine (10 $\mu \mathrm{m})$ and MLA (10 nM), sEPSC events in ECV neurons were significantly increased after brief $(350 \mathrm{~ms}$ ) local application of ACh to ECVI neurons, but not after the application of ACh to either ECIII or neighboring ECV neurons. A glutamatergic receptor inhibitor, CNQX (20 $\mu \mathrm{m})$, completely blocked the sEPSC events. The slow inward current in the recordings was consistent with the direct activation of $n A C h R s$ on the recorded ECV neuron.
When we increased the duration of local application of ACh to the ECVI region to $1 \mathrm{~min}$, we could now observe a significant increase in the frequency of sIPSC events in ECV neurons (Fig. 7B), demonstrating that inhibitory synaptic connections from ECVI to ECV neurons exist but they are relatively harder to activate. Increases in the frequency of sIPSCs did not occur when ACh was locally applied to the ECV or ECIII regions similar distances away from the recorded ECV neuron (Fig. $7 B$ ), demonstrating that non- $\alpha 7$ nAChRcontaining inhibitory neurons that target ECV neurons exist mainly in the ECVI region. This increase in sIPSC frequency recorded from ECV neurons was also blocked by DH $\beta \mathrm{E}(1 \mu \mathrm{M} ; n=3)$ (Fig. 7C), further confirming that these inhibitory ECVI neurons innervating ECV neurons were activated by ACh through the activation of non- $\alpha 7 \mathrm{nAChRs}$. The increase in sIPSC frequency in ECV neurons was also prevented by pretreatment of TTX $(1 \mu \mathrm{M} ; n=3)$ (Fig. $7 D)$, indicating that the increase in sIPSC frequency was a result of increased action potential frequency, not a consequence of higher synaptic vesicle release probability (often attributable to increased intracellular calcium in presynaptic terminals). Statistical analysis revealed a significant decrease in sIPSC interval by the local application of ACh to ECVI neurons $(n=5)$ (Fig. 7E), further suggesting that ECVI GABAergic neurons may provide a major source of inhibitory synaptic influence during systematic non- $\alpha 7$ nAChR activation.

Low concentration of nicotine enhances both amplitude and plasticity in Sb-ECVI synapses

Since we found that both the Sb and ECVI contain nicotine-sensitive neurons, and it is known that $\mathrm{Sb}$ neurons project to the 
ECVI (van Strien et al., 2009), we studied the effect of nicotine on Sb-ECVI synapses by recording evoked EPSCs (eEPSCs) from ECVI neurons while stimulating the $\mathrm{Sb}$ near the CA1 region. The bath application of a low concentration of nicotine $(0.1 \mu \mathrm{M})$ increased the eEPSC amplitude by $40 \pm 2 \%(n=5)$ (Fig. $8 A)$. The increase in eEPSC amplitude was also observed when nicotine was applied locally to the recorded ECVI neuron $(33 \pm 3 \%$; $n=6$ ) (Fig. $8 A$ ), and this effect was blocked by either $\mathrm{DH} \beta \mathrm{E}(0.1 \mu \mathrm{M})$ (Fig. $8 C$ ) or MLA (10 nM) (Fig. $8 D$, compare filled symbols), demonstrating that the enhancement of Sb-ECVI synaptic transmission by nicotine is mediated by both $\alpha 7$ and non- $\alpha 7 \mathrm{nAChRs}$ at a nicotine concentration related to smoking. The PPR, which is inversely related to the presynaptic neurotransmitter release probability (Dobrunz and Stevens, 1997; Lagostena et al., 2008), was $1.70 \pm 0.05$ $(n=6)$ under control conditions and decreased significantly to $1.22 \pm 0.08(n=$ 6) after the local application of nicotine, suggesting a presynaptic mechanism of action (Fig. $8 E$ ).

Next we examined whether nicotine had any effect on synaptic plasticity in ECVI neurons. A tetanus stimulation (100 $\mathrm{Hz}, 100 \mathrm{~ms}$ ) delivered to the $\mathrm{Sb}$ region elicited STP $(<20 \mathrm{~min})$ in the Sb-ECVI synapses (Fig. $8 B$ ). When the tetanus was preceded by the local perfusion of nicotine $(0.1 \mu \mathrm{M})$ for $10 \mathrm{~min}$, the STP was boosted to long-term potentiation (LTP; $>50 \mathrm{~min}$ ), an effect that was blocked by the non- $\alpha 7 \mathrm{nAChR}$ antagonist $\mathrm{DH} \beta \mathrm{E}$ ( 1 $\mu \mathrm{M})$ (Fig. $8 C$ ). Interestingly, the PPR during STP and LTP (1.72 \pm 0.11 and $1.58 \pm 0.07$, respectively; $n=3$ ) was not significantly different from control (1.69 \pm 0.15 and $1.65 \pm 0.1$, respectively; $n=3$ ), suggesting that this enhancement is attributable to a postsynaptic mechanism of action.

The bath application of the $\alpha 7$-selective antagonist MLA (10 $\mathrm{nm}$ ) appeared to prevent the presynaptic action of nicotine since under these conditions, nicotine failed to enhance the amplitude of the eEPSC and alter the PPR in the presence of MLA (Fig. 8D,E). However, STP was still boosted to LTP (Fig. $8 D$ ). These data suggest that nicotine (at a concentration similar to the blood level in cigarette smokers) is acting presynaptically to enhance glutamate release via the activation of $\alpha 7 \mathrm{nAChRs}$ on presynaptic terminals and, in addition, is acting postsynaptically via non- $\alpha 7$ nAChRs to convert STP to LTP. A further indication of a postsynaptic mechanism of action for LTP is that dialyzing ECVI neurons with the calcium chelator BAPTA $(10 \mathrm{~mm}) \mathrm{re}-$ duced the extent of LTP (30 min after the tetanus) by $70 \%$ (from 82 to $25 \%$ ) (Fig. $8 D$ ).


Figure 7. Nicotine-sensitive ECVI neurons also influenced GABAergic inputs to pyramidal neurons in ECV. $\boldsymbol{A}$, In the presence of atropine $(10 \mu \mathrm{M}), \mathrm{NBQX}(20 \mu \mathrm{m})$, and APV $(25 \mu \mathrm{M})$, sIPSCs were recorded from an ECV neuron when voltage clamped at $-80 \mathrm{mV}$ with a KCl-based internal solution containing QX314. There was no significant change in sIPSC frequency with bath-applied nicotine ( $\mathrm{Nic} ; 10 \mu \mathrm{m} ; p>0.05$, KS test in pooled data of 3 neurons; cumulative probability data not shown). The $\mathrm{GABA}_{\mathrm{A}}$ receptor blocker gabazine $(1 \mu \mathrm{M})$ was applied at the end of the experiment to verify that the events were mediated by $G_{A B A}$ receptors. Calibration: horizontal, 2 min; vertical, $50 \mathrm{pA}$. Note that this ECV neuron had a much less evident nicotine-induced current response than that of Figure 6 , which is a reflection of variability in nicotine responses among ECV neurons demonstrated in Table 1. $\boldsymbol{B}$, Increases in SIPSC frequency were observed in an ECV neuron during longer-duration (1 min) local applications of ACh ( $4 \mathrm{~mm})$ to the $\mathrm{ECVI}$ region (second trace) but not to ECIII, ECV, or control regions in the presence of antagonists to muscarinic AChRs (10 $\mu \mathrm{m}$

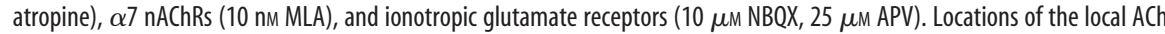
applications were the same as in Figure $6 \mathrm{~B}$. The recordings were performed using a CsGluc-based internal solution containing QX314, and the neuron was voltage clamped at $0 \mathrm{mV}$. Calibration: horizontal, $1 \mathrm{~min}$; vertical, $50 \mathrm{pA}$ (also applies to $\boldsymbol{C}$ and $\boldsymbol{D}$ ). $\boldsymbol{C}$, Increase in sIPSC events was recorded in an ECV neuron during local ACh application to the ECVI region (same condition as $\boldsymbol{B}$ ). This increase was blocked by $1 \mu \mathrm{m} \mathrm{DH} \beta \mathrm{E}$, which was partially reversed by the removal of $\mathrm{DH} \beta \mathrm{E}$ for $20 \mathrm{~min}$. At the end of experiments, all sIPSCs were eliminated by gabazine $(1 \mu \mathrm{M})$. D, Increases in sIPSC events recorded in ECV neurons during local ACh application to the ECVI region were eliminated by $1 \mu \mathrm{m}$ TTX, demonstrating that the influence of ECVI neurons toward ECV neurons requires action potential firing. $\boldsymbol{E}$, Pooled results from five neurons demonstrated that intervals of sIPSC events (Int) in ECV neurons were decreased by the activation of non- $\alpha 7$ nAChR-containing neurons in ECVI but not in ECV or ECIII.

\section{Discussion}

We found that ECVI, a region in the HF not previously known to participate in the effects of nicotine, contains neurons that are highly responsive to nicotine under conditions that emulate the delivery of nicotine during smoking. These ECVI neurons were primarily glutamatergic with high RMPs and low h-currents and were capable of influencing synaptic activity to ECV neurons (i.e., by enhancing glutamatergic and GABAergic synaptic responses). In addition, the occurrence of LTP at Sb-ECVI synapses was facilitated by nicotine at a low concentration related to cigarette smoking. Therefore, future investigations focusing on the deep layers of the EC region are critical for our under- 

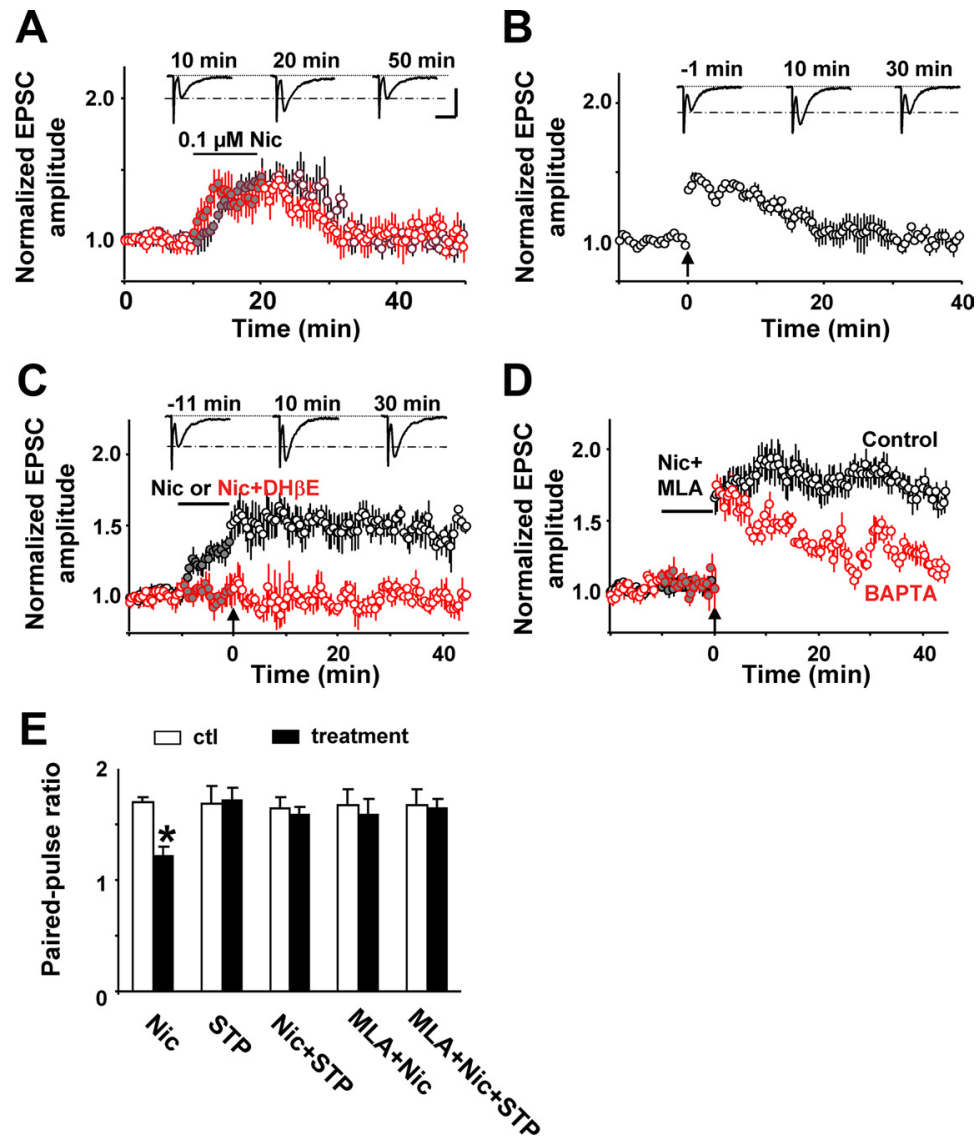

Figure 8. Nicotine selectively enhances synaptic transmission and plasticity in Sb-EC synapses. A, Both bath (black circles) and local (red circles) application of nicotine (Nic; $0.1 \mu \mathrm{m}$ ) for 10 min increased the amplitude of EPSCs recorded from ECVI neurons evoked by single stimuli. Data points and error bars represent mean and SEM of eEPSCs recorded before (open circles), during (closed circles), and after (open circles afterward) the bath $(n=5)$ or local $(n=6)$ nicotine application. Representative traces on top were derived from bath-application experiments at indicated time points. Calibration: $50 \mathrm{pA}, 20 \mathrm{~ms}$ (also applies to $\boldsymbol{B}$ and $\boldsymbol{C}$ ). $B$, Tetanic stimulation $(100 \mathrm{~Hz}, 100 \mathrm{~ms}$; arrow) in the Sb area induced STP in ECVI neurons $(n=5)$. Top traces represent eEPSCs at the indicated time points. C, Local application of nicotine (Nic; $0.1 \mu \mathrm{M}$ ) for $10 \mathrm{~min}$ to the recorded ECVI neuron boosted the STP to LTP (black circles; $n=7)$. When applied together with DH $\beta E(1 \mu \mathrm{M})$, nicotine neither increased eEPSC amplitude nor boosted STP into LTP (red circles; $n=5$ ). Representative top traces were derived from eEPSC of the nicotine experiment at the indicated time points. D, MLA (10 nM) blocked the increase in eEPSC amplitude by nicotine (Nic) but failed to stop generation of LTP (black circles; $n=6)$. However, after dialyzing cells with the calcium chelator BAPTA ( $10 \mathrm{~mm}$; red circles; $n=4)$, nicotine failed to boost STP into LTP. E, PPR before (open bars) and after (closed bars) various treatments. Nic, Nicotine alone $(n=6) ;$ STP, short-term potentiation after tetanic stimulation ( $n=3) ; \mathrm{Nic}+$ STP, STP preceded by nicotine treatment $(n=3) ; \mathrm{MLA}+\mathrm{Nic}$, MLA coapplied with nicotine $(n=4) ;$ MLA + Nic + STP, STP preceded by MLA and nicotine application. ${ }^{*}$ Significantly different from control $(p<0.01$, Students $t$ test).

standing of the cellular mechanisms of nicotine action and the potential role of nicotine in regulating memory.

\section{Identification of nicotine-sensitive neuronal populations in brain slices using VSDI}

In this study, we used the VSDI method to map the functional distribution of nicotine receptors to facilitate localization of nicotine-sensitive neuronal populations in hippocampal slices. VSDI is a relatively new technology in neuroscience (Takashima et al., 1999) that is a functional assay that offers high spatial and temporal resolution for imaging neocortical functions in living brain (Grinvald and Hildesheim, 2004). Although patch-clamp functional assays have superior sensitivity and reliability, the time-consuming nature of this single-cell approach does not easily lend itself to recordings from all cellular types in all brain regions. Thus, we used the VSDI technique to locate large areas of functional nAChRs that were activated by nicotine in the HF and used patch-clamp techniques to identify neuronal types in known locations of brain slices to characterize the functional properties of these responses. Future improvements in the sensitivity of the VSDI technique (e.g., more stable and sensitive dyes and better cameras) will undoubtedly increase the usefulness of this method for the functional mapping of other ion channels.

\section{The $\alpha 4 \beta 2$ and $\alpha 7$ are the most likely nAChR subtypes responsible for nicotine effects in ECVI neurons} Thus far, six $\alpha$ and three $\beta \mathrm{nAChR}$ subunits $(\alpha 2-7, \beta 2-4)$ have been identified in neurons of the mammalian brain, with the most prevalent nAChRs in the hippocampus and cortex composed of the $\alpha 7$ and $\alpha 4 \beta 2$ subtypes (Wada et al., 1989; Sargent, 1993; Alkondon and Albuquerque, 2004). We have demonstrated the existence of functional $\alpha 7$ subunit-containing nAChRs in ECVI neurons based on their kinetics and pharmacological properties (Figs. 3-5).

For the non- $\alpha 7$ nAChR-mediated responses, the $\alpha 2, \alpha 3$, and $\alpha 6$ subunits have not previously been found in deep EC layers, whereas both the $\alpha 4$ and $\beta 2$ subunits have (Wada et al., 1989; Boyd, 1997; Sudweeks and Yakel, 2000; Mugnaini et al., 2002). In addition the $\alpha 5$ and $\beta 3$ subunits are auxiliary subunits that carry no agonist binding sites (Ramirez-Latorre et al., 1996; Wang et al., 1996). Therefore, the most likely subunit composition of the non- $\alpha 7 \mathrm{nAChRs}$ mediating the nicotineinduced effects in the ECVI neurons are either the $\alpha 4 \beta 2$ or $\alpha 4 \beta 4$ subtypes. This composition is consistent with the fact that the nAChRs in ECVI neurons were almost completely inhibited $(>90 \%)$ by a low concentration of $\mathrm{DH} \beta \mathrm{E}(1 \mu \mathrm{M})$ (Harvey et al., 1996; Chavez-Noriega et al., 1997; Marks et al., 1999). Since $\alpha 4 \beta 2$ nAChRs are the most prevalent non- $\alpha 7$ nAChRs in the hippocampus and cortex (both of these subunits have previously been found to be expressed in the deep layers of the EC) and the nicotine sensitivity of $\alpha 4 \beta 2 \mathrm{nAChRs}$ (Briggs et al., 2006) is close to what we have observed in ECVI neurons (Fig. $3 D$ ), the $\alpha 4 \beta 2$ subtype is the most likely non- $\alpha 7 \mathrm{nAChR}$ subtype responsible for nicotine effects in the EC. However, we cannot completely rule out that other nAChR subunits, including the $\alpha 5$, $\beta 3$, and $\beta 4$ subunits, might be contributing. For example, the differences in nicotine sensitivity and decay rates among responses in CA1, SbSO, and ECVI neurons (Fig. 3) may be attributable to several possible mechanisms, including differences in the molecular makeup of the nAChRs (see above).

\section{ECVI neurons may be important in mediating the effects of} nicotine on memory

Our results suggest that ECVI neurons may be an important target of nicotine action in the HF. Studies regarding the 
mechanisms of nicotine influence on the HF have been primarily focused on the dentate gyrus and hippocampal proper regions (Jones and Yakel, 1997; Dani and Bertrand, 2007) where nicotine-sensitive neurons are mainly inhibitory GABAergic interneurons that express both $\alpha 7$ and non- $\alpha 7$ nAChRs (Alkondon and Albuquerque, 1993; Jones and Yakel, 1997; McQuiston and Madison, 1999; Frazier et al., 2003). Our data from both VSDI and patch-clamp recordings indicate that neurons from the deep EC layers (in particular ECVI) and SbSO, the portion of the Sb close to the deep EC layers, had larger responses to bath-applied nicotine (through the activation of non- $\alpha 7 \mathrm{nAChRs)} \mathrm{compared}$ with the CA1 interneurons. All neurons that were studied in the ECVI, as well as most in the ECV, expressed functional non- $\alpha 7$ nAChRs, more so than the percentage of CA1 interneurons expressing non- $\alpha 7$ nAChRs. Because the bath application of low concentrations of nicotine $(0.1 \mu \mathrm{M})$ to slices emulates the systematic introduction of nicotine during smoking $(0.06-0.31 \mu \mathrm{M})$, or nicotine injection (Moriya and Hashimoto, 2004; Hukkanen et al., 2005; Moriya et al., 2006), the present study suggests that ECVI neurons may be an important site of nicotine action in the HF; this will have to be verified in future studies in vivo. These data are also consistent with a previous report in which nicotineinduced seizures upregulated immediate-early genes more in the EC regions that in other areas of the HF (Bastlund et al., 2005). Although most ECVI neurons had functional $\alpha 7 \mathrm{nAChRs}$ that were activated when the agonist was locally applied, these $\alpha 7$ receptors were not activated with bath-applied nicotine because of rapid desensitization. However, the expression of these receptors in the ECVI neurons also may be very important because of their influences on intracellular calcium concentration and potential role in influencing learning and memory in human and animal models (Welsby et al., 2006, 2007).

To investigate possible influences that the activation of ECVI neurons may have on other regions of the HF, we studied possible synaptic inputs to ECV neurons. These were chosen because their dendrites extend deep into the ECVI layer (Hamam et al., 2000; Egorov et al., 2003) and are in close proximity to each other. Direct connections from the ECVI to ECII/III, or more remotely to CA1 and dentate gyrus (Dugladze et al., 2001), are also likely but were not examined in this study. We found that the bath application of nicotine $(10 \mu \mathrm{M})$ significantly enhanced glutamatergic but not GABAergic postsynaptic events recorded in the ECV neurons. In addition, brief (350 ms) local application of high concentrations of ACh (4 mM) to neurons in the ECVI region increase sEPSC events within $10 \mathrm{~s}$ of application, which did not occur when ACh application was applied to other regions of the EC. These results indicate that ECVI neurons provide an important source of excitatory synaptic influence to ECV neurons.

Although brief local application of ACh to ECVI neurons failed to increase sIPSC events in ECV neurons, more prolonged (1 min) local application of ACh to ECVI neurons significantly enhanced the frequency of GABAergic postsynaptic currents (sIPSC) in ECV neurons. This demonstrates that ECVI neurons also provide inhibitory synaptic influences to ECV neurons; however, these inhibitory effects were harder to activate and/or involved fewer ECVI neurons. These results suggest that under our experimental conditions, when the non- $\alpha 7$ nAChRs on ECVI neurons are activated, the enhancement of excitatory glutamatergic neuronal inputs to ECV neurons overcomes any possible inhibition caused by increases in neuronal GABAergic activities. This is consistent with our findings that the nicotine-responsive ECVI neurons are primarily pyramidal- or multipolar-shaped neurons, which are mainly excitatory in nature (Hamam et al., 2000).
We also demonstrated that a low concentration of nicotine $(0.1$ $\mu \mathrm{M}$ ) enhances synaptic transmission (through presynaptic $\alpha 7$ and non- $\alpha 7$ nAChRs) and converts STP to LTP at Sb-ECVI synapses (through postsynaptic non- $\alpha 7 \mathrm{nAChRs)} \mathrm{in} \mathrm{a} \mathrm{cytoplasmic} \mathrm{calcium-}$ dependent pathway. A nicotine-dependent enhancement in plasticity was previously reported in synapses in CA1 and dentate regions through activation of $\alpha 7 \mathrm{nAChRs}$ (Fujii et al., 1999; Ji et al., 2001; Mann and Greenfield, 2003; Welsby et al., 2006, 2007), but it required a much higher concentration of nicotine (i.e., 1-5 $\mu \mathrm{M}$ ). Our finding that non- $\alpha 7 \mathrm{nAChRs}$ also contributes to the facilitation of LTP occurrence is consistent with a recent report that $\alpha 4$-containing nAChRs contribute to LTP facilitation (Nashmi et al., 2007). These data further suggest that ECVI neurons may play a significant role in learning and memory during smoking.

Based on these results, we postulate that during smoking, ECVI neurons influence hippocampal excitability through their projection to ECV and maybe other regions (including ECII/III, dentate, and CA1 regions) and also potentiate synaptic transmission to ECVI neurons from Sb neurons. Additional studies are needed to better understand the role of ECVI neurons in the influence of nicotine on memory.

\section{References}

Airan RD, Meltzer LA, Roy M, Gong Y, Chen H, Deisseroth K (2007) Highspeed imaging reveals neurophysiological links to behavior in an animal model of depression. Science 317:819-823.

Alkondon M, Albuquerque EX (1993) Diversity of nicotinic acetylcholine receptors in rat hippocampal neurons. I. Pharmacological and functional evidence for distinct structural subtypes. J Pharmacol Exp Ther 265:1455-1473.

Alkondon M, Albuquerque EX (2001) Nicotinic acetylcholine receptor alpha7 and alpha4beta2 subtypes differentially control GABAergic input to CA1 neurons in rat hippocampus. J Neurophysiol 86:3043-3055.

Alkondon M, Albuquerque EX (2002) A non-alpha7 nicotinic acetylcholine receptor modulates excitatory input to hippocampal CA1 interneurons. J Neurophysiol 87:1651-1654.

Alkondon M, Albuquerque EX (2004) The nicotinic acetylcholine receptor subtypes and their function in the hippocampus and cerebral cortex. Prog Brain Res 145:109-120.

Alkondon M, Reinhardt S, Lobron C, Hermsen B, Maelicke A, Albuquerque EX (1994) Diversity of nicotinic acetylcholine receptors in rat hippocampal neurons. II. The rundown and inward rectification of agonistelicited whole-cell currents and identification of receptor subunits by in situ hybridization. J Pharmacol Exp Ther 271:494-506.

Amaral DG, Witter MP (1995) Hippocampal formation. In: The rat nervous system (George P, ed), p 444. Sydney: Academic.

Aponte Y, Lien CC, Reisinger E, Jonas P (2006) Hyperpolarizationactivated cation channels in fast-spiking interneurons of rat hippocampus. J Physiol 574:229-243.

Bastlund JF, Berry D, Watson WP (2005) Pharmacological and histological characterisation of nicotine-kindled seizures in mice. Neuropharmacology 48:975-983.

Blozovski D (1983) Deficits in passive avoidance learning in young rats following mecamylamine injections in the hippocampo-entorhinal area. Exp Brain Res 50:442-448.

Blozovski D (1985) Mediation of passive avoidance learning by nicotinic hippocampo-entorhinal components in young rats. Dev Psychobiol 18:355-366.

Boyd RT (1997) The molecular biology of neuronal nicotinic acetylcholine receptors. Crit Rev Toxicol 27:299-318.

Briggs CA, Gubbins EJ, Marks MJ, Putman CB, Thimmapaya R, Meyer MD, Surowy CS (2006) Untranslated region-dependent exclusive expression of high-sensitivity subforms of alpha4beta 2 and alpha3beta2 nicotinic acetylcholine receptors. Mol Pharmacol 70:227-240.

Burhans LB, Gabriel M (2007) Contextual modulation of conditioned responses: role of the ventral subiculum and nucleus accumbens. Behav Neurosci 121:1243-1257.

Chavez-Noriega LE, Crona JH, Washburn MS, Urrutia A, Elliott KJ, Johnson EC (1997) Pharmacological characterization of recombinant human 
neuronal nicotinic acetylcholine receptors $\mathrm{h}$ alpha 2 beta 2 , h alpha 2 beta 4 , h alpha 3 beta 2 , h alpha 3 beta 4 , h alpha 4 beta 2, h alpha 4 beta 4 and $\mathrm{h}$ alpha 7 expressed in Xenopus oocytes. J Pharmacol Exp Ther 280:346-356.

Chen L, Gong S, Shan LD, Xu WP, Zhang YJ, Guo SY, Hisamitsu T, Yin QZ, Jiang XH (2006) Effects of exercise on neurogenesis in the dentate gyrus and ability of learning and memory after hippocampus lesion in adult rats. Neurosci Bull 22:1-6.

Chrobak JJ, Buzsaki G (1994) Selective activation of deep layer (V-VI) retrohippocampal cortical neurons during hippocampal sharp waves in the behaving rat. J Neurosci 14:6160-6170.

Dajas-Bailador F, Wonnacott S (2004) Nicotinic acetylcholine receptors and the regulation of neuronal signalling. Trends Pharmacol Sci 25:317-324.

Dani JA, Bertrand D (2007) Nicotinic acetylcholine receptors and nicotinic cholinergic mechanisms of the central nervous system. Annu Rev Pharmacol Toxicol 47:699-729.

Davis JA, Kenney JW, Gould TJ (2007) Hippocampal $\alpha 4 \beta 2$ nicotinic acetylcholine receptor involvement in the enhancing effect of acute nicotine on contextual fear conditioning. J Neurosci 27:10870-10877.

Deadwyler SA, Hampson RE (2004) Differential but complementary mnemonic functions of the hippocampus and subiculum. Neuron 42:465-476.

Deller T, Martinez A, Nitsch R, Frotscher M (1996) A novel entorhinal projection to the rat dentate gyrus: direct innervation of proximal dendrites and cell bodies of granule cells and GABAergic neurons. J Neurosci 16:3322-3333.

Dobrunz LE, Stevens CF (1997) Heterogeneity of release probability, facilitation, and depletion at central synapses. Neuron 18:995-1008.

Dolorfo CL, Amaral DG (1998) Entorhinal cortex of the rat: organization of intrinsic connections. J Comp Neurol 398:49-82.

Dugladze T, Heinemann U, Gloveli T (2001) Entorhinal cortex projection cells to the hippocampal formation in vitro. Brain Res 905:224-231.

Ebner TJ, Chen G (1995) Use of voltage-sensitive dyes and optical recordings in the central nervous system. Prog Neurobiol 46:463-506.

Egorov AV, Angelova PR, Heinemann U, Muller W (2003) Ca2+independent muscarinic excitation of rat medial entorhinal cortex layer $\mathrm{V}$ neurons. Eur J Neurosci 18:3343-3351.

Fayuk D, Yakel JL (2004) Regulation of nicotinic acetylcholine receptor channel function by acetylcholinesterase inhibitors in rat hippocampal CA1 interneurons. Mol Pharmacol 66:658-666.

Fayuk D, Yakel JL (2005) Ca2+ permeability of nicotinic acetylcholine receptors in rat hippocampal CA1 interneurones. J Physiol 566:759-768.

Frazier CJ, Rollins YD, Breese CR, Leonard S, Freedman R, Dunwiddie TV (1998a) Acetylcholine activates an $\alpha$-bungarotoxin-sensitive nicotinic current in rat hippocampal interneurons, but not pyramidal cells. J Neurosci 18:1187-1195.

Frazier CJ, Buhler AV, Weiner JL, Dunwiddie TV (1998b) Synaptic potentials mediated via $\alpha$-bungarotoxin-sensitive nicotinic acetylcholine receptors in rat hippocampal interneurons. J Neurosci 18:8228-8235.

Frazier CJ, Strowbridge BW, Papke RL (2003) Nicotinic receptors on local circuit neurons in dentate gyrus: a potential role in regulation of granule cell excitability. J Neurophysiol 89:3018-3028.

Fujii S, Ji Z, Morita N, Sumikawa K (1999) Acute and chronic nicotine exposure differentially facilitate the induction of LTP. Brain Res 846:137-143.

Fujii S, Ji Z, Sumikawa K (2000) Inactivation of alpha7 ACh receptors and activation of non-alpha7 ACh receptors both contribute to long term potentiation induction in the hippocampal CA1 region. Neurosci Lett 286:134-138.

Gnatkovsky V, de Curtis M (2006) Hippocampus-mediated activation of superficial and deep layer neurons in the medial entorhinal cortex of the isolated guinea pig brain. J Neurosci 26:873-881.

Gray R, Rajan AS, Radcliffe KA, Yakehiro M, Dani JA (1996) Hippocampal synaptic transmission enhanced by low concentrations of nicotine. Nature 383:713-716.

Grinvald A, Hildesheim R (2004) VSDI: a new era in functional imaging of cortical dynamics. Nat Rev Neurosci 5:874-885.

Hamam BN, Kennedy TE, Alonso A, Amaral DG (2000) Morphological and electrophysiological characteristics of layer $\mathrm{V}$ neurons of the rat medial entorhinal cortex. J Comp Neurol 418:457-472.

Harich S, Kinfe T, Koch M, Schwabe K (2008) Neonatal lesions of the ento- rhinal cortex induce long-term changes of limbic brain regions and maze learning deficits in adult rats. Neuroscience 153:918-928.

Harvey SC, Maddox FN, Luetje CW (1996) Multiple determinants of dihydro-beta-erythroidine sensitivity on rat neuronal nicotinic receptor alpha subunits. J Neurochem 67:1953-1959.

Hasselmo ME (2005) The role of hippocampal regions CA3 and CA1 in matching entorhinal input with retrieval of associations between objects and context: theoretical comment on Lee et al. (2005). Behav Neurosci 119:342-345.

He J, Deng CY, Zhu XN, Yu JP, Chen RZ (2003) Different synaptic mechanisms of long-term potentiation induced by nicotine and tetanic stimulation in hippocampal CA1 region of rats. Acta Pharmacol Sin 24:398-402.

Hukkanen J, Jacob P, Benowitz NL (2005) Metabolism and disposition kinetics of nicotine. Pharmacol Rev 57:79-115.

Hunsaker MR, Lee B, Kesner RP (2008) Evaluating the temporal context of episodic memory: the role of CA3 and CA1. Behav Brain Res 188:310-315.

Hunter BE, de Fiebre CM, Papke RL, Kem WR, Meyer EM (1994) A novel nicotinic agonist facilitates induction of long-term potentiation in the rat hippocampus. Neurosci Lett 168:130-134.

Hurst RS, Hajos M, Raggenbass M, Wall TM, Higdon NR, Lawson JA, Rutherford-Root KL, Berkenpas MB, Hoffmann WE, Piotrowski DW, Groppi VE, Allaman G, Ogier R, Bertrand S, Bertrand D, Arneric SP (2005) A novel positive allosteric modulator of the $\alpha 7$ neuronal nicotinic acetylcholine receptor: in vitro and in vivo characterization. J Neurosci 25:4396-4405.

Insausti R, Herrero MT, Witter MP (1997) Entorhinal cortex of the rat: cytoarchitectonic subdivisions and the origin and distribution of cortical efferents. Hippocampus 7:146-183.

Izquierdo I, Cammarota M, Silva WC, Bevilaqua LR, Rossato JI, Bonini JS, Mello P, Benetti F, Costa JC, Medina JH (2008) The evidence for hippocampal long-term potentiation as a basis of memory for simple tasks. An Acad Bras Cienc 80:115-127.

Ji D, Lape R, Dani JA (2001) Timing and location of nicotinic activity enhances or depresses hippocampal synaptic plasticity. Neuron 31:131-141.

Jones S, Yakel JL (1997) Functional nicotinic ACh receptors on interneurones in the rat hippocampus. J Physiol 504:603-610.

Khiroug L, Giniatullin R, Klein RC, Fayuk D, Yakel JL (2003) Functional mapping and $\mathrm{Ca}^{2+}$ regulation of nicotinic acetylcholine receptor channels in rat hippocampal CA1 neurons. J Neurosci 23:9024-9031.

Klein RC, Yakel JL (2005) Paired-pulse potentiation of alpha7-containing nAChRs in rat hippocampal CAl stratum radiatum interneurones. J Physiol 568:881-889.

Klink R, de Kerchove d'Exaerde A, Zoli M, Changeux JP (2001) Molecular and physiological diversity of nicotinic acetylcholine receptors in the midbrain dopaminergic nuclei. J Neurosci 21:1452-1463.

Kohler C (1986) Intrinsic connections of the retrohippocampal region in the rat brain. II. The medial entorhinal area. J Comp Neurol 246:149-169.

Lagostena L, Trocme-Thibierge C, Morain P, Cherubini E (2008) The partial alpha7 nicotine acetylcholine receptor agonist S 24795 enhances longterm potentiation at CA3-CA1 synapses in the adult mouse hippocampus. Neuropharmacology 54:676-685.

Lee I, Hunsaker MR, Kesner RP (2005) The role of hippocampal subregions in detecting spatial novelty. Behav Neurosci 119:145-153.

Levin ED, Rezvani AH (2002) Nicotinic treatment for cognitive dysfunction. Curr Drug Targets CNS Neurol Disord 1:423-431.

Levin ED, McClernon FJ, Rezvani AH (2006) Nicotinic effects on cognitive function: behavioral characterization, pharmacological specification, and anatomic localization. Psychopharmacology (Berl) 184:523-539.

Li JS, Chao YS (2008) Electrolytic lesions of dorsal CA3 impair episodic-like memory in rats. Neurobiol Learn Mem 89:192-198.

Loew LM, Cohen LB, Dix J, Fluhler EN, Montana V, Salama G, Wu JY (1992) A naphthyl analog of the aminostyryl pyridinium class of potentiometric membrane dyes shows consistent sensitivity in a variety of tissue, cell, and model membrane preparations. J Membr Biol 130:1-10.

Lupica CR, Bell JA, Hoffman AF, Watson PL (2001) Contribution of the hyperpolarization-activated current $(\mathrm{I}(\mathrm{h}))$ to membrane potential and GABA release in hippocampal interneurons. J Neurophysiol 86:261-268.

Mann EO, Greenfield SA (2003) Novel modulatory mechanisms revealed by the sustained application of nicotine in the guinea-pig hippocampus in vitro. J Physiol 551:539-550. 
Mann EO, Suckling JM, Hajos N, Greenfield SA, Paulsen O (2005) Perisomatic feedback inhibition underlies cholinergically induced fast network oscillations in the rat hippocampus in vitro. Neuron 45:105-117.

Marks MJ, Whiteaker P, Calcaterra J, Stitzel JA, Bullock AE, Grady SR, Picciotto MR, Changeux JP, Collins AC (1999) Two pharmacologically distinct components of nicotinic receptor-mediated rubidium efflux in mouse brain require the beta2 subunit. J Pharmacol Exp Ther 289:1090-1103.

Martin-Fardon R, Ciccocioppo R, Aujla H, Weiss F (2007) The dorsal subiculum mediates the acquisition of conditioned reinstatement of cocaineseeking. Neuropsychopharmacology 33:1827-1834.

Matsuyama S, Matsumoto A, Enomoto T, Nishizaki T (2000) Activation of nicotinic acetylcholine receptors induces long-term potentiation in vivo in the intact mouse dentate gyrus. Eur J Neurosci 12:3741-3747.

McGehee DS, Role LW (1996) Neurobiology: memories of nicotine. Nature 383:670-671.

McQuiston AR, Madison DV (1999) Nicotinic receptor activation excites distinct subtypes of interneurons in the rat hippocampus. J Neurosci 19:2887-2896.

Moriya F, Hashimoto Y (2004) Nicotine and cotinine levels in blood and urine from forensic autopsy cases. Leg Med (Tokyo) 6:164-169.

Moriya F, Furumiya J, Hashimoto Y (2006) [Nicotine and cotinine levels in body fluids of habitual smokers who committed suicide]. Nihon Arukoru Yakubutsu Igakkai Zasshi 41:504-512.

Mugnaini M, Tessari M, Tarter G, Merlo Pich E, Chiamulera C, Bunnemann B (2002) Upregulation of [3H]methyllycaconitine binding sites following continuous infusion of nicotine, without changes of alpha7 or alpha6 subunit mRNA: an autoradiography and in situ hybridization study in rat brain. Eur J Neurosci 16:1633-1646.

Munoz M, Insausti R (2005) Cortical efferents of the entorhinal cortex and the adjacent parahippocampal region in the monkey (Macaca fascicularis). Eur J Neurosci 22:1368-1388.

Naber PA, Lopes da Silva FH, Witter MP (2001) Reciprocal connections between the entorhinal cortex and hippocampal fields CA1 and the subiculum are in register with the projections from CA1 to the subiculum. Hippocampus 11:99-104.

Nashmi R, Xiao C, Deshpande P, McKinney S, Grady SR, Whiteaker P, Huang Q, McClure-Begley T, Lindstrom JM, Labarca C, Collins AC, Marks MJ, Lester HA (2007) Chronic nicotine cell specifically upregulates functional alpha $4^{*}$ nicotinic receptors: basis for both tolerance in midbrain and enhanced long-term potentiation in perforant path. J Neurosci 27:8202-8218.

O’Mara SM, Commins S, Anderson M, Gigg J (2001) The subiculum: a review of form, physiology and function. Prog Neurobiol 64:129-155.

Park HJ, Lee PH, Ahn YW, Choi YJ, Lee G, Lee DY, Chung ES, Jin BK (2007) Neuroprotective effect of nicotine on dopaminergic neurons by antiinflammatory action. Eur J Neurosci 26:79-89.

Paxinos G, Watson C (2007) The rat brain in stereotaxic coordinates, Vol 1, Ed 6. New York: Academic.

Peeke SC, Peeke HV (1984) Attention, memory, and cigarette smoking. Psychopharmacology (Berl) 84:205-216.

Pidoplichko VI, Dani JA (2005) Applying small quantities of multiple compounds to defined locations of in vitro brain slices. J Neurosci Methods 142:55-66.

Poisik OV, Shen JX, Jones S, Yakel JL (2008) Functional alpha7-containing nicotinic acetylcholine receptors localize to cell bodies and proximal dendrites in the rat substantia nigra pars reticulata. J Physiol 586:1365-1378.

Potter AS, Newhouse PA (2008) Acute nicotine improves cognitive deficits in young adults with attention-deficit/hyperactivity disorder. Pharmacol Biochem Behav 88:407-417.

Quik M, Bordia T, O’Leary K (2007a) Nicotinic receptors as CNS targets for Parkinson's disease. Biochem Pharmacol 74:1224-1234.

Quik M, Cox H, Parameswaran N, O'Leary K, Langston JW, Di Monte D (2007b) Nicotine reduces levodopa-induced dyskinesias in lesioned monkeys. Ann Neurol 62:588-596.

Ramirez-Latorre J, Yu CR, Qu X, Perin F, Karlin A, Role L (1996) Func- tional contributions of alpha5 subunit to neuronal acetylcholine receptor channels. Nature 380:347-351.

Rosenbaum T, Gordon SE (2004) Quickening the pace: looking into the heart of HCN channels. Neuron 42:193-196.

Ruan YW, Zou B, Fan Y, Li Y, Lin N, Zhang Y, Xu ZC (2007) Morphological heterogeneity of CA1 pyramidal neurons in response to ischemia. J Neurosci Res 85:193-204.

Sajikumar S, Li Q, Abraham WC, Xiao ZC (2009) Priming of short-term potentiation and synaptic tagging/capture mechanisms by ryanodine receptor activation in rat hippocampal CA1. Learn Mem 16:178-186.

Sargent PB (1993) The diversity of neuronal nicotinic acetylcholine receptors. Annu Rev Neurosci 16:403-443.

Sawada S, Yamamoto C, Ohno-Shosaku T (1994) Long-term potentiation and depression in the dentate gyrus, and effects of nicotine. Neurosci Res 20:323-329.

Shin EJ, Chae JS, Jung ME, Bing G, Ko KH, Kim WK, Wie MB, Cheon MA, Nah SY, Kim HC (2007) Repeated intracerebroventricular infusion of nicotine prevents kainate-induced neurotoxicity by activating the alpha7 nicotinic acetylcholine receptor. Epilepsy Res 73:292-298.

Siu CW, Lieu DK, Li RA (2006) HCN-encoded pacemaker channels: from physiology and biophysics to bioengineering. J Membr Biol 214:115-122.

Solger J, Wozny C, Manahan-Vaughan D, Behr J (2004) Distinct mechanisms of bidirectional activity-dependent synaptic plasticity in superficial and deep layers of rat entorhinal cortex. Eur J Neurosci 19:2003-2007.

Sudweeks SN, Yakel JL (2000) Functional and molecular characterization of neuronal nicotinic ACh receptors in rat CAl hippocampal neurons. J Physiol 527:515-528.

Takashima I, Ichikawa M, Iijima T (1999) High-speed CCD imaging system for monitoring neural activity in vivo and in vitro, using a voltagesensitive dye. J Neurosci Methods 91:147-159.

Timmermann DB, Gronlien JH, Kohlhaas KL, Nielsen EO, Dam E, Jorgensen TD, Ahring PK, Peters D, Holst D, Chrsitensen JK, et al (2007) An allosteric modulator of the alpha7 nicotinic acetylcholine receptor possessing cognition-enhancing properties in vivo. J Pharmacol Exp Ther 323:294-307.

Tizabi Y (2007) Nicotine and nicotinic system in hypoglutamatergic models of schizophrenia. Neurotox Res 12:233-246.

Tominaga T, Tominaga Y, Yamada H, Matsumoto G, Ichikawa M (2000) Quantification of optical signals with electrophysiological signals in neural activities of Di-4-ANEPPS stained rat hippocampal slices. J Neurosci Methods 102:11-23.

Van Cauter T, Poucet B, Save E (2008) Delay-dependent involvement of the rat entorhinal cortex in habituation to a novel environment. Neurobiol Learn Mem 90:192-199.

van Strien NM, Cappaert NL, Witter MP (2009) The anatomy of memory: an interactive overview of the parahippocampal-hippocampal network. Nat Rev Neurosci 10:272-282.

Villafane G, Cesaro P, Rialland A, Baloul S, Azimi S, Bourdet C, Le Houezec J, Macquin-Mavier I, Maison P (2007) Chronic high dose transdermal nicotine in Parkinson's disease: an open trial. Eur J Neurol 14:1313-1316.

Wada E, Wada K, Boulter J, Deneris E, Heinemann S, Patrick J, Swanson LW (1989) Distribution of alpha 2, alpha 3, alpha 4, and beta 2 neuronal nicotinic receptor subunit mRNAs in the central nervous system: a hybridization histochemical study in the rat. J Comp Neurol 284:314-335.

Wang F, Gerzanich V, Wells GB, Anand R, Peng X, Keyser K, Lindstrom J (1996) Assembly of human neuronal nicotinic receptor alpha5 subunits with alpha3, beta2, and beta4 subunits. J Biol Chem 271:17656-17665.

Welsby P, Rowan M, Anwyl R (2006) Nicotinic receptor-mediated enhancement of long-term potentiation involves activation of metabotropic glutamate receptors and ryanodine-sensitive calcium stores in the dentate gyrus. Eur J Neurosci 24:3109-3118.

Welsby PJ, Rowan MJ, Anwyl R (2007) Beta-amyloid blocks high frequency stimulation induced LTP but not nicotine enhanced LTP. Neuropharmacology 53:188-195.

Wyss JM, Van Groen T (1992) Connections between the retrosplenial cortex and the hippocampal formation in the rat: a review. Hippocampus 2:1-11. 